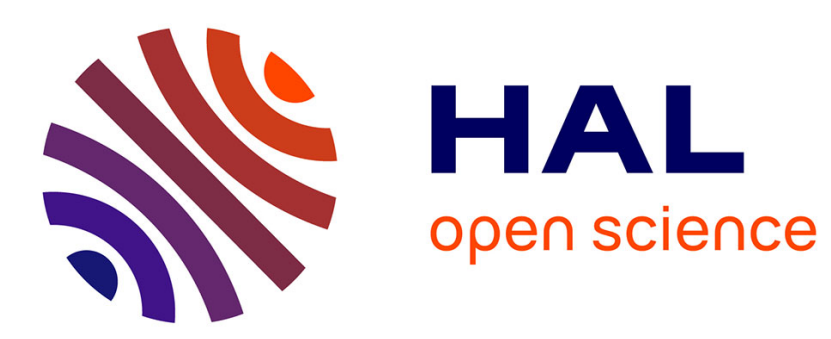

\title{
The impact of EITC on education, labor market trajectories, and inequalities
}

Julien Albertini, Arthur Poirier, Anthony Terriau

\section{To cite this version:}

Julien Albertini, Arthur Poirier, Anthony Terriau. The impact of EITC on education, labor market trajectories, and inequalities. 2020. halshs-03082382

\section{HAL Id: halshs-03082382 \\ https://shs.hal.science/halshs-03082382}

Preprint submitted on 18 Dec 2020

HAL is a multi-disciplinary open access archive for the deposit and dissemination of scientific research documents, whether they are published or not. The documents may come from teaching and research institutions in France or abroad, or from public or private research centers.
L'archive ouverte pluridisciplinaire HAL, est destinée au dépôt et à la diffusion de documents scientifiques de niveau recherche, publiés ou non, émanant des établissements d'enseignement et de recherche français ou étrangers, des laboratoires publics ou privés. 
UMR 5824

93. chemin des Mouilles 69130 Ecully - France

Maison de l'Universite, Bâtiment B 10, rue Trefilerie 42023 Saint-Etienne cedex $02 \cdot$ France

http://www.gate.cnrs.fr gate@gate.cnrs.fr

\title{
The impact of EITC on education, labor market trajectories, and inequalities
}

\author{
Julien Albertini, Arthur Poirier, Anthony Terriau
}

\begin{abstract}
:
As a complement to the federal EITC, some states offer their own EITC, typically calculated as a percentage of the federal EITC. In this paper, we analyze the effect of state EITC on education using policy discontinuities at U.S. state borders. Our estimates reveal that an increase in state EITC leads to a statistically significant drop in high school completion. We then use a life-cycle matching model with directed search and endogenous educational choices, search intensities, hirings, hours worked, and separations to investigate the effects of EITC on the labor market in the long run and along the transitional dynamics. We show that a tax credit targeted at low-wage (and low-skilled) workers reduces the relative return to schooling, thereby generating a powerful disincentive to pursue long-term studies. In the long run, this results in an increase in the proportion of lowskilled workers in the economy, which may have important implications in terms of employment, productivity, and income inequalities.
\end{abstract}

\section{Keywords:}

EITC, Education, Human capital, Search and matching, Life cycle

JEL codes:

D15, E24, H24, I24, J24, J6

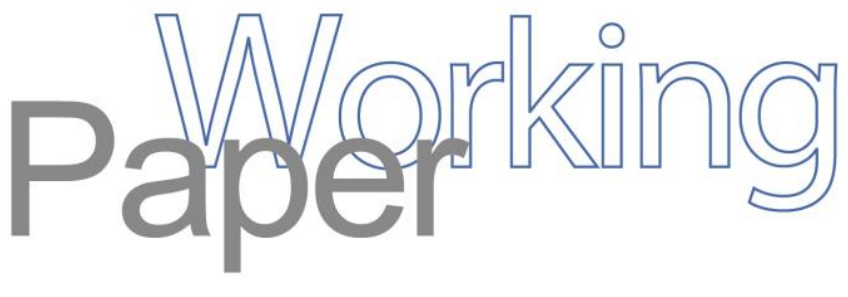




\title{
The impact of EITC on education, labor market trajectories, and inequalities
}

\author{
Julien Albertini* $\quad$ Arthur Poirier ${ }^{\dagger} \quad$ Anthony Terriau ${ }^{\ddagger}$
}

December 16, 2020

\begin{abstract}
As a complement to the federal EITC, some states offer their own EITC, typically calculated as a percentage of the federal EITC. In this paper, we analyze the effect of state EITC on education using policy discontinuities at U.S. state borders. Our estimates reveal that an increase in state EITC leads to a statistically significant drop in high school completion. We then use a life-cycle matching model with directed search and endogenous educational choices, search intensities, hirings, hours worked, and separations to investigate the effects of EITC on the labor market in the long run and along the transitional dynamics. We show that a tax credit targeted at low-wage (and low-skilled) workers reduces the relative return to schooling, thereby generating a powerful disincentive to pursue long-term studies. In the long run, this results in an increase in the proportion of low-skilled workers in the economy, which may have important implications in terms of employment, productivity, and income inequalities.
\end{abstract}

JEL Classification: D15; E24; H24; I24; J24; J6

Keywords: EITC; Education; Human capital; Search and matching; Life cycle

*Univ Lyon, Université Lumière Lyon 2, GATE UMR 5824, F-69130 Ecully, France

†GAINS, University of Le Mans

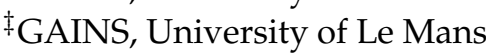




\section{Introduction}

The Earned Income Tax Credit (EITC) is a federal refundable tax credit targeted at lowincome workers. Enacted by the Congress in 1975, the EITC has gradually become one of the most important anti-poverty programs in the U.S . In 2020, the direct cost of the EITC to the U.S. federal government was about $\$ 70$ billion $(0.35 \%$ of the GDP).

The EITC was designed to "reward work" and increase the worker incentive to participate in the labor market. The program is supposed to be "self-financed" through increases in employment and rises in tax revenue. Because of the objectives of this tax credit, most of the literature has focused on the work incentive effects of EITC. Empirical research suggests that the EITC mainly affects the female labor supply, increasing the labor force participation of single mothers (Eissa and Liebman, 1996; Meyer and Rosenbaum, 2001) but reducing the workforce participation of married women, while it slightly increases the participation of married men (Eissa and Hoynes, 2004). Some empirical studies also suggest that the EITC affects the intensive margin, depending on the phase of the EITC where the worker is located (Hoffman and Seidman, 1990; Dickert et al., 1995).

While informative, these studies mainly address the short-term effects of EITC through labor force participation and hours worked, and thus tell only part of the story. As highlighted by Blundell et al. (2016), in-work benefits may have longer-term effects by affecting educational choices and labor market trajectories over the life-cycle. In their literature review, Nichols and Rothstein (2015) questioned the potential perverse effects of EITC on educational attainment decisions and pointed out the lack of research on this topic.

As shown by Wasmer (2006) and Chéron et al. (2011), the returns of human capital investments predominantly depend on search frictions in the labor market. When search is directed, which is supported by recent empirical studies (Banfi and VillenaRoldan, 2019), educational decisions have a significant impact on labor market trajectories by affecting both job-finding probabilities and labor incomes over the lifecycle (Chéron and Terriau, 2018; Albertini and Terriau, 2019). In such a framework, in-work benefits targeted at low-paid (and low-skilled) workers increase the value of low-skilled employment and reduce the relative return of high-skilled jobs. As a result, the EITC may act as a disincentive to pursue further studies.

In our paper, we estimate the effect of EITC on education, taking inspiration from the minimum wage literature (Dube et al., 2010; Hagedorn et al., 2015). We exploit the fact that, from the mid-1980s, some states implemented their own EITC (state EITC), set as a percentage of the federal credit. We take advantage of the American Community Survey (ACS), which provides yearly information on education, employment, hours worked, and earnings for a variety of geographic areas, for data based on which we compare all contiguous Public Use Microdata Area (PUMA) pairs in the U.S. that are located on opposite sides of a state border. Our empirical strategy, based on contiguous PUMA pairs and policy discontinuities at state borders, suggests that EITC has a negative and significant impact on education.

This result indicates that the EITC may have non-trivial consequences on labor market outcomes and income inequalities. First, all other things being equal, the EITC increases the earnings of low-skilled workers. Second, by making low-skilled jobs more attractive, the EITC reduces the return of education, thereby discouraging some young people from pursuing further studies beyond high school. Third, the EITC may affect 
unemployed workers, by increasing the marginal gain from search effort, but also employed workers, who may respond by adjusting the number of hours worked. This may affect both the employment rate and the average net income. Finally, the educational system response (the change in the proportion of low-skilled workers) and the labor market response (the changes in search effort, hours worked, job creation, and job destruction decisions) generate an ambiguous effect on long-run net income inequalities.

We develop an original theoretical framework to quantify the general equilibrium effects and to disentangle the different channels through which the EITC affects labor market trajectories. Our model builds on the dynamic labor supply model literature (Heckman and MaCurdy, 1980), in particular models highlighting the key role of education on life-cycle earnings (Keane and Wolpin, 1997, 2007, 2010; Blundell et al., 2016). In our paper, we develop a life-cycle matching model with directed search in which educational choices, search intensities, hirings, hours worked, and separations are endogenous. Contrary to Menzio et al. (2016), who supposed an exogenous human capital accumulation process, we consider that individuals choose their human capital investment before entering the labor market, in line with the work of Acemoglu (1996) Decreuse and Granier (2013), Albertini and Terriau (2019), and Abbott et al. (2019). We solve and estimate the model and show that it replicates accurately the life-cycle profile of several labor market variables, including the income distribution and the distribution of workers across the different phases of the EITC.

We then investigate the effects of an increase in the generosity of the EITC. While such a scenario increases the search intensity of skilled and unskilled unemployed workers, it modifies the composition of the labor force, by reducing the return of education and increasing the proportion of low-skilled workers, which translates into a substantial fall in total employment. Furthermore, we show that the EITC encourages workers located in the phase-out range and outside the EITC schedule (the vast majority of workers) to reduce the number of hours worked to benefit from the program. As a consequence, aggregate hours worked decreases, thereby mitigating the extra income coming from the EITC. When taking into account both the educational system response and the labor market response, we show that the EITC does not achieve a significant reduction in income inequalities in the long run.

Our paper highlights the paradox of the EITC: it encourages the participation of low-paid workers but it also provides incentives to be a low-paid worker. People react to an increase in EITC by leaving school early and reducing hours of work. As a result, in the long run, the total employment rate declines and the net income of lowskilled workers does not increase as much as expected, which considerably limits the redistributive effects of the EITC

The rest of the paper is organized as follows: Section 2 describes the database and the empirical strategy used to estimate the effect of EITC on education, and presents the results and the robustness tests. Section 3 discusses some important assumptions of the model. Section 4 presents the theoretical framework. Section 5 describes the procedure used to estimate the structural parameters of the model and compare the moments generated by the model to their empirical counterparts. In Section 6, we use our model to explore the long-term effects of EITC as well as the transitional dynamics. A final section concludes. 


\section{Empirical framework}

\subsection{Federal EITC and state EITC}

The federal EITC is a benefit for working people with low-income. The federal EITC varies based on the recipient's earnings and number of children. Its schedule is characterized by three regions: the "phase-in region", where the EITC equals a fixed percentage (the "phase-in rate") of earned income; the "plateau region", where the EITC remains at its maximum level (the "maximum credit"); and the "phase-out region", where the EITC decreases to zero at a fixed rate (the "phase-out rate"). For the 2018 tax year, the maximum tax credit for a tax filer without children is $\$ 519 ;$; $\$ 3461$ with one child; $\$ 5716$ with two children; and $\$ 6431$ for three children or more. The credit may represent up to $45 \%$ of earned income. ${ }^{1}$. The phase-in (phase-out) rates equal $7.65 \%$ $(7.65 \%), 34.00 \%$ (15.98\%), $40.00 \%$ (21.06\%), and $45.00 \%$ (21.06\%), respectively (Figure 1). The federal EITC parameters vary across time (mainly in response to inflation) and are described in Appendix A.

Figure 1: Federal EITC, 2018

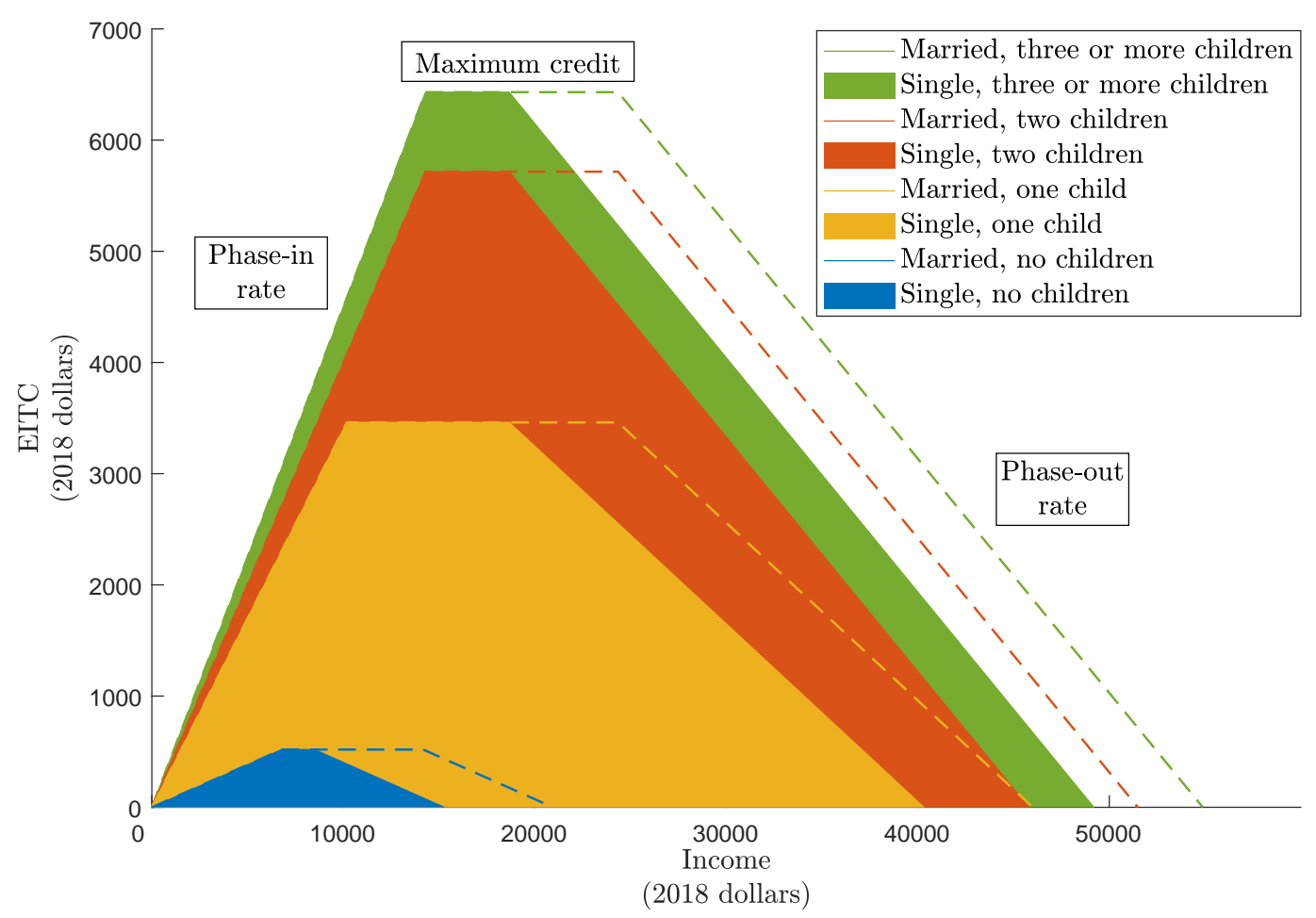

Source: Internal Revenue Service

As a complement to the federal EITC, some states offer their own EITC, typically calculated as a percentage of the federal credit ${ }^{2}$ (see Appendix B). In 2005, 14 states and the District of Columbia had EITC provisions in their income tax laws. In 2018,

\footnotetext{
${ }^{1}$ For a tax filer with three children or more who earned $\$ 14290$, i.e., the minimum earned income to benefit from the maximum tax credit.

${ }^{2}$ The only exception is California, which has implemented a state EITC (from 2015) that is not expressed as a percentage of the federal EITC.
} 
11 more states offered their own EITC (see Figure 2). There are substantial differences in treatment intensity across states: i) There are 45 state-level changes in EITC over the period 2005-2018; ii) the state EITC (expressed as a percentage of the federal credit) varies across states and time from $3.5 \%$ to $50 \%$; and iii) no state has the same EITC path as another state over the period considered.

The fact that some states have implemented the same policy (a state EITC set as a \% of the federal EITC) but with different intensities (different \%) offers a unique opportunity to identify the effects of in-work benefits on education. Our empirical strategy is detailed in the next subsections.

Figure 2: State EITC, 2018

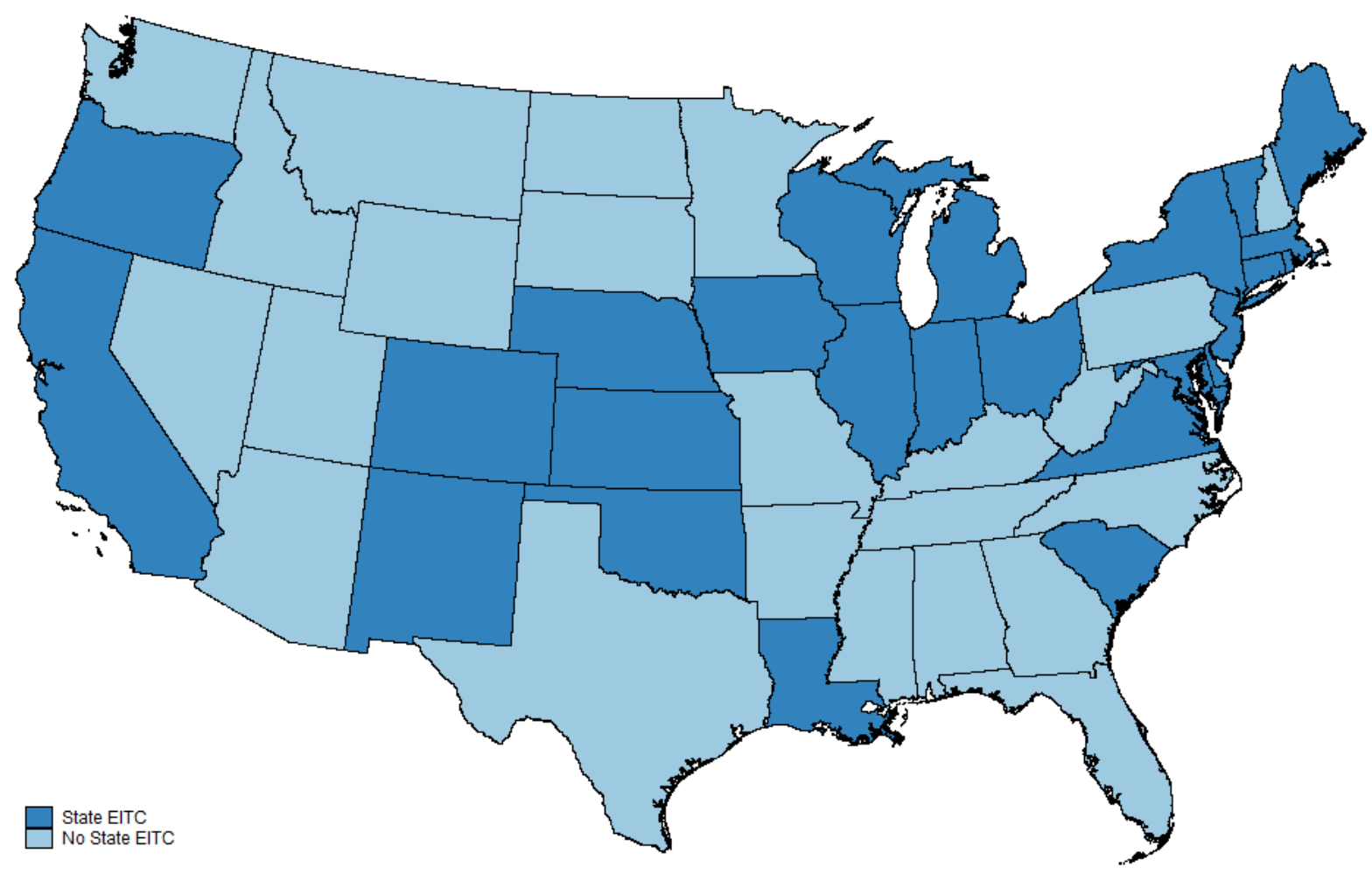

Source: ACS 1-year

\subsection{Data}

We take advantage of the American Community Survey (ACS) for the period 2005 to 2018. The ACS is the largest household survey in the U.S. (1-in-100 national random sample of the population). Each wave of the ACS contains more than 3 million observations. The ACS provides yearly information on education, employment, hours worked, and earnings. More interestingly, data from the ACS are gathered for a variety of geographic areas (nation, regions, states, etc.). The smallest identifiable geographic unit in the ACS 1-year is the Public Use Microdata Area or "PUMA". Each state is divided by the Census Bureau into PUMAs with at least 100,000 people. PUMAs are constructed based on county and neighborhood boundaries and do not cross state lines. Typically, counties with large populations are subdivided into multiple PUMAs, while PUMAs in more rural areas comprise groups of adjacent counties. 
In this study, we propose to identify the effect of EITC on education by using policy discontinuities at state borders. We compare all contiguous PUMA-pairs sharing a state border (see Figure 3 for an example). As highlighted by Holmes (1998), Huang (2008), Dube et al. (2010), and Hagedorn et al. (2015), local economic areas represent good control groups for at least two reasons: i) the policy (state EITC) is determined at the state level and is largely exogenous from the point of view of an individual PUMA; ii) contiguous border PUMAs are relatively similar, in particular with regard to employment, earnings, and education trends. Said differently, using PUMAs as units of analysis allows minimizing endogeneity issues and makes the common trend assumption much more credible.

Figure 3: Contiguous border PUMA pairs - Example for the states of New York and Pennsylvania 


\subsubsection{Sample}

Our sample consists of all the contiguous PUMA-pairs that straddle a state boundary in the U.S. mainland. As a result, Alaska and Hawaii, which do not share a border with other states, are excluded from the analysis. We also exclude California, which has implemented a state EITC (from 2015) that is not expressed as a percentage of the federal EITC. Finally, we exclude New Jersey and Wisconsin, the only two states where the credit rate depends on the number of children. ${ }^{3}$ Our final sample includes 45 states and the District of Columbia. Among the 897 PUMAs, 314 lie along a state border. As each PUMA may belong to several PUMA-pairs, we have a total of 401 distinct PUMA-pairs. Some descriptive statistics are provided in Table 1.

\subsubsection{Variables}

Our goal is to estimate the effect of EITC on education. In our empirical framework, the outcome is the high school completion rate, defined as the percentage of 18- to 24-yearolds who have left high school and who hold a high school credential. This indicator was chosen for four reasons: i) Schooling is compulsory until the age of 18 in most states; ii) This indicator is used by the U.S. Department of Education to analyze high school dropouts over time (McFarland et al., 2020); iii) This measure is fully comparable across space and time; and iv) Among all grades, this is the grade around which earnings differences are the most important (the hourly wage of a worker who completed high school is $60 \%$ higher than that of a worker who did not).

As shown in Table 1, on average, among 18- to 24-year-olds who are not enrolled in high school or a lower education level, $91.34 \%$ hold a high school diploma or alternative credential. Almost half of the states offer their own EITC, representing on average $7.54 \%$ of the federal EITC. We also report some statistics relative to the population aged 18 to 24 who have left high school.

\footnotetext{
${ }^{3}$ Including these two states and considering the credit rates for specific filing status leads to similar conclusions.
} 
Table 1: Descriptive statistics

\begin{tabular}{lrr}
\hline \hline & Mean & s.d. \\
\hline \hline States & & \\
State EITC & 0.0754 & 0.1269 \\
& & \\
18- to 24-year-olds who have left high school & & \\
Male & 0.5105 & 0.0455 \\
White & 0.7952 & 0.1547 \\
Black & 0.1127 & 0.1366 \\
Employed & 0.6023 & 0.0889 \\
High school completed & 0.9134 & 0.0469 \\
\hline \hline Number of PUMAs & 314 & 314 \\
Number of PUMA-pairs & 401 & 401 \\
Number of states & 46 & 46 \\
\hline \hline
\end{tabular}

Sample means are reported for all contiguous border PUMA-pairs.

Source: ACS 1-year, 2005-2018 


\subsection{Empirical strategy}

Let $i$ denote the PUMA, $p$ the PUMA-pair, and $t$ the time. For identification, we estimate the following model:

$$
Y_{i p t}=\alpha_{0}+\beta_{e} E_{i t}+\beta_{x} X_{i t}+\mu_{i}+\omega_{p t}+\epsilon_{i p t}
$$

where $Y$ is the high school completion rate, $E$ is the state EITC (as a percentage of the federal EITC), $X$ is a set of control variables, $\mu_{i}$ represents a PUMA fixed effect, $\omega_{p t}$ a pair-time fixed effect, and $\epsilon_{i p t}$ is the error term. Note that $X$ captures changes in the demographic characteristics of the population aged 18 to 24 (sex, race), changes in the parental environment (parental education, income, marital status, and number of EITC-eligible children), changes in labor market conditions (employment rate), and changes in state policy variables, including welfare (percentage of recipients, and average amount by recipient). To account for serial and spatial correlations in the residuals, we follow the procedure described by Dube et al. (2010) to compute the standard errors.

Table 2: EITC effect on education

\begin{tabular}{lc}
\hline \hline VARIABLES & \\
\hline \hline State EITC & $-0.0720^{* *}$ \\
& $(0.0350)$ \\
Controls & \\
PUMA-pair $\times$ period dummies & YES \\
Demographic characteristics & YES \\
Parental environment & YES \\
Labor market conditions & YES \\
State policy variables & YES \\
\hline \hline Number of periods & 14 \\
Number of PUMA-pairs & 401 \\
R-squared & 0.8061 \\
\hline \hline Standard errors in parentheses. ${ }^{* * *} \mathrm{p}<0.01,{ }^{* *} \mathrm{p}<0.05,{ }^{*} \mathrm{p}<0.1$. \\
\multicolumn{2}{c}{ Source: ACS 1-year, $2005-2018$} \\
\end{tabular}

Our estimates reveal that a 1-percentage-point increase in state EITC (as a percentage of the federal EITC) leads to a statistically significant drop in the high school completion rate of 0.07 percentage points $^{4}$ (see Table 2 ).

\subsection{Spillover effects}

Our results may be affected by spillover effects if, in response to states welfare and taxation policies, individuals move to a contiguous PUMA located on the other side of the state border (Tiebout, 1956; Cebula and Alexander, 2006). When the EITC differs across neighboring states, one would expect low-skilled individuals to move to states where the EITC is more generous. The interstate mobility is more likely when individuals live in counties located at the state border, where the moving cost is relatively low.

\footnotetext{
${ }^{4}$ Note that our results are robust to a large number of alternative specifications.
} 
To test for spillover effects, we follow the strategy adopted by Huang (2008). Instead of comparing two PUMAs sharing a state border, we now compare a PUMA located at the state border with a co-contiguous interior PUMA, that is, a PUMA which is:

1. not immediately adjacent

2. separated by only one PUMA

3. not located at the state border

4. located on the opposite side of the state border

The first two conditions state that the control PUMA is co-contiguous to the treated PUMA, with the contiguous border PUMA between them. The two last conditions indicate that the control PUMA is interior, i.e., located in the hinterland.

Figure 4: Robustness test - Alternative control group to test for spillover effects

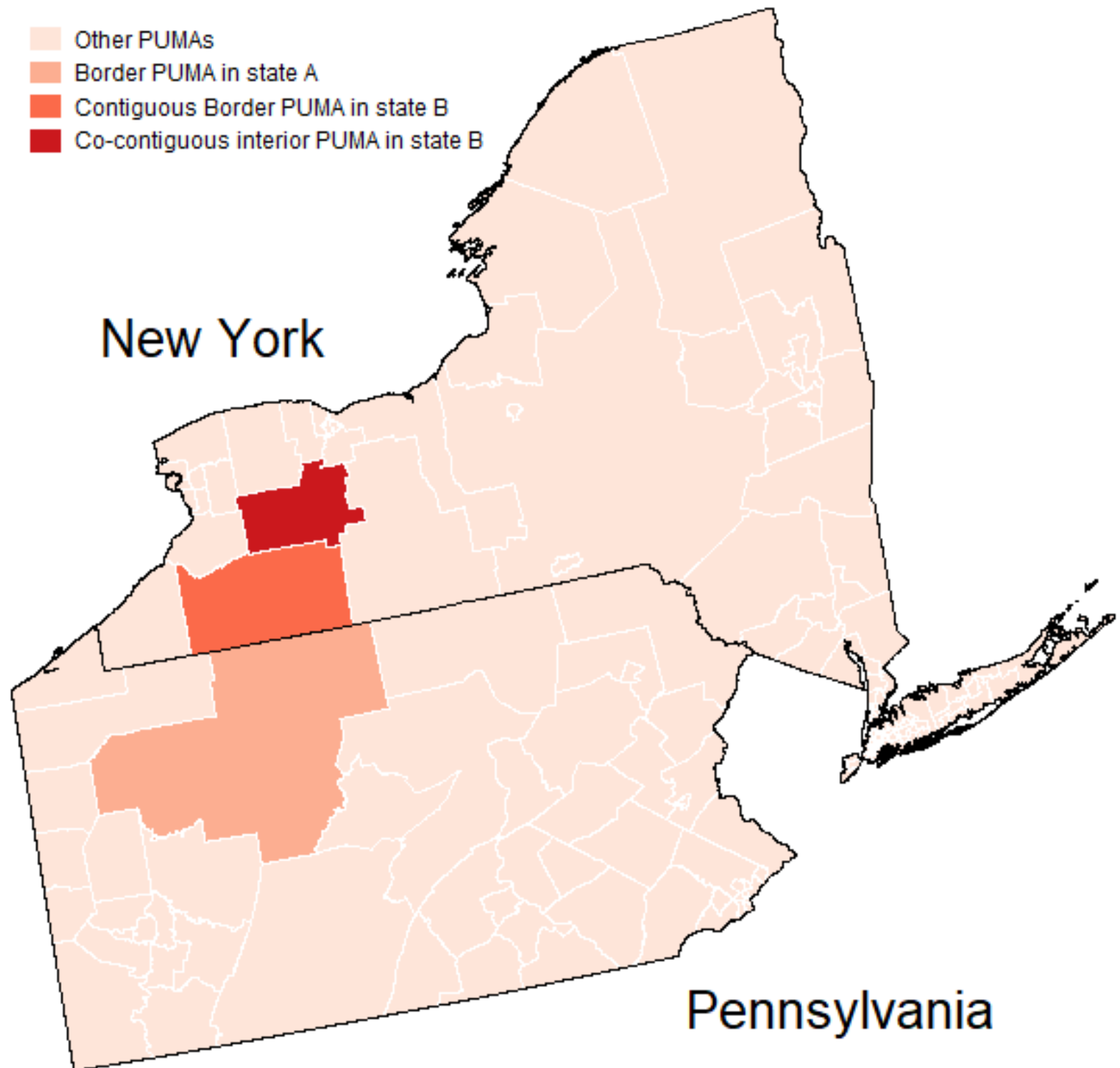

Source: ACS 1-year 
For the sake of clarity, an example is provided in Figure 4. Consider a PUMA (in pale orange) located in Pennsylvania and sharing a border with New York. The contiguous border PUMA (in dark orange) represents the control PUMA in the benchmark estimation, while the co-contiguous interior PUMA (in red) represents the control PUMA in the robustness test. If there were spillover effects, they should decrease with the distance from the border. Estimates using co-contiguous interior PUMAs, which are farther away from state borders, should be less affected by spillover effects. Using this alternative control group, our conclusions remain unchanged (see Appendix C). An increase in state EITC significantly reduces the high school completion rate, suggesting that our results are not driven by spillover effects.

\section{Modeling choices}

In this section, we document empirical facts that motivate some modeling assumptions. We pay special attention to hours worked, hourly wage, and net social transfer in order to reproduce as closely as possible the labor market response to EITC.

\subsection{Hours worked}

The expected impact of the EITC on hours worked varies across the different regions of the credit. In the "phase-in region", the substitution effect provides an incentive to increase hours worked, whereas the income effect provides an incentive to decrease hours worked, so the net effect is ambiguous. In the "plateau region", there is only a negative income effect leading to an unambiguous reduction in hours worked. In the "phase-out region", the substitution and income effects work in the same direction and both unambiguously provide an incentive to decrease hours worked. While empirical studies provide mixed results when considering specific population groups (men/women, single/married, without/with children, etc.), research conducted on the whole population of EITC recipients confirms that hours worked increase in the "phase-in" range and decrease in the "plateau" and "phase-out" ranges (Hoffman and Seidman, 1990; Dickert et al., 1995). As the vast majority of EITC recipients are located on the "phase-out" range (Hoffman and Seidman, 2003), the EITC is expected to reduce average hours of work, conditional on working. In our model, we consider that hours worked may vary with EITC as a result of the worker's optimal decision.

\subsection{Hourly wage}

Predictions regarding the long-term impact of EITC on life-cycle trajectories crucially depend on its effects on wages. In the search and matching literature, the conventional approach consists in using a generalized Nash criterion to determine wages. Nash bargaining implies that employers may capture some of the tax credit by reducing pretax hourly wages. However, empirical research suggests that the impact of EITC on pre-tax hourly wages is close to zero (Hoffman and Seidman, 2003). Why are pre-tax hourly wages so rigid? A first argument is that a large part of EITC recipients are paid at the minimum wage, so that employers cannot put downward pressure on pre-tax hourly wages (Eissa and Nichols, 2005). A second argument that can explain the wage stickiness is that employers do not know whether their employees receive the credit 
or not (Nichols and Rothstein, 2015). Until 2011, EITC recipients could receive a fraction of their credit with each paycheck rather than a lump sum at tax-filing time via the advance EIC program. Opting for this program required submitting a withholding election form to the employer. However, as noted by Moffitt (2016), only 3\% of EITC recipients opted for this program, leading to its cancellation. Such behaviors suggest that workers preferred that their employers not know that they were receiving EITC. As employers do not have information about the eligibility or the amount of EITC received by their employees, it is not surprising to observe no significant effect on pre-tax hourly wages. From a theoretical point of view, the modest impact of in-work benefits on wages has led economists to consider that the best way to describe the labor supply response is to consider a labor supply model with exogenous pre-tax hourly wages and endogenous intensive margin (Keane and Moffitt, 1998; Saez, 2002; Blundell, 2006; Blundell et al., 2016). In our model, we consider that pre-tax hourly wages are fixed and depend on education, human capital, and idiosyncratic productivity.

\subsection{Net social transfer}

The EITC may affect life-cycle earnings in two ways: Directly as an in-work benefit but also indirectly, as the adjustments in education and labor market cause changes in pre-tax income that induce variations in eligibility for other programs. Ignoring the indirect effect of EITC on other programs leads to a misestimation of its effects on education, labor supply responses, life-cycle earnings, and inequalities. To take into account incentives from the transfer system, we follow the approach proposed by Blundell et al. (2016). More precisely, we compute the net social transfer (welfare less taxes), depending on age, family status, education, and labor force status (see Appendix D.4 for more details). We then have a value for net social transfer that can be cast into the model's state-space. This allows us to capture the whole structure of the transfer system (a complex non-concave and discontinuous function of income, age, education, labor force status, and family status) in a tractable way.

\section{Model}

We develop a life-cycle matching model with directed search in which educational choices, search intensities, hirings, hours worked, and separations are endogenous. Adjustment of employment occurs along the intensive and the extensive margin.

\subsection{Heterogeneities}

Age. As in Chéron et al. (2013), workers differ according to their age $a=\left\{a_{0}, a_{1}, \ldots, a_{A}\right\}$. The life-cycle spans from age $a_{0}=16$ to age $a_{A}=69$. Age increases deterministically, so that the next period age is $a^{\prime}=a+1$. In each period, the oldest generation of workers retires and a new generation of the same size enters the labor force. This implies that the size of the labor force is constant. The fraction of the labor force retiring and entering is thus equal to $1 /\left(a_{A}-a_{0}\right) \simeq 2 \%$.

Educational attainment. As in Albertini and Terriau (2019), each individual chooses her educational attainment $e \in \Omega_{e}$ before entering the labor market, with $\Omega_{e}=\left\{e_{1}, e_{2}\right\}$. 
$e_{1}$ corresponds to no educational attainment or equivalently less than high school, and $e_{2}$ corresponds to either high school or college degree. We assume that once an individual enters the labor market, educational attainment is fixed until retirement. The optimal educational decision is detailed later.

Human capital. We consider human capital accumulation as a learning-by-doing process. It refers to the experience accumulated while employed. The human capital $h$ has a finite discrete support $h=\left\{h_{1}, \ldots, h_{H}\right\}$. After completing her education (low or high), each individual enters the labor market as unemployed with the lowest human capital level $\left(h=h_{1}\right)$. Human capital may appreciate during employment and depreciate during unemployment spells. Furthermore, we assume that the human capital is general in the sense of Becker (1962). As a consequence, a laid-off worker with human capital $h>h_{1}$ may find a new job and start with the same level of human capital, provided that her human capital does not depreciate during the unemployment spell. In the spirit of Ljungqvist and Sargent (1998), Ljungqvist and Sargent (2008), and Lalé (2018), we consider two Markov process to characterize the gradual transitions in human capital. Formally, we have:

$$
\begin{aligned}
& \mu_{n}\left(h, h^{\prime}\right)=\left\{\begin{array}{lll}
1-\psi_{n} & \text { if } h<h_{H} \text { and } h^{\prime}=h, \\
\psi_{n} & \text { if } h<h_{H} \text { and } h^{\prime}=h+1 .
\end{array}\right. \\
& \mu_{u}\left(h, h^{\prime}\right)=\left\{\begin{array}{lll}
1-\psi_{u} & \text { if } h>h_{1} \text { and } h^{\prime}=h \\
\psi_{u} & \text { if } h>h_{1} \text { and } h^{\prime}=h-1 .
\end{array}\right.
\end{aligned}
$$

It is worth mentioning that an employed individual with $h=h_{H}$ cannot further accumulate human capital and $\mu_{n}\left(h, h^{\prime}\right)=1$. Symmetrically, for an unemployed worker with $h=h_{1}$, the human capital cannot further depreciate, as $\mu_{u}\left(h, h^{\prime}\right)=1$.

Family status. We consider each household as belonging to one of four family statuses $(f)$ : 0 child, 1 child, 2 children, or 3 or more children. $f=\left\{f_{0}, f_{1}, f_{2}, f_{3}\right\}$. As in Blundell et al. (2016), we assume that the family status evolves stochastically. ${ }^{5}$ The new family status $f^{\prime}$ is drawn each period according to a conditional distribution $G_{a, e}\left(f^{\prime} \mid f\right)$ with density $g_{a, e}\left(f^{\prime} \mid f\right)$. The distribution is skill- and age- dependent to capture the observed evolution of the family status across groups with different educational attainment and over the life-cycle. In particular, it allows us to capture two important features of the dynamics of family composition: i) Educated workers tend to have children later and to have fewer of them, as they spend more time in the educational system; and ii) the probability of having eligible children is not constant over the lifecycle: it increases up to age 40 and decreases thereafter (see Appendix H).

Idiosyncratic productivity $x$ denotes the idiosyncratic productivity component of an employed worker. It evolves according to a Markov process. The new individual productivity $x^{\prime}$ is drawn from the conditional distribution $Z\left(x^{\prime} \mid x\right)$. For a new match, a new individual productivity $x^{\prime}$ is drawn from an unconditional distribution $Z_{0}\left(x^{\prime}\right)$.

\footnotetext{
${ }^{5}$ The decision to have children is thus unrelated to the labor market situation. Introducing such a concept would certainly enrich the model but is likely to drastically complicate the analysis.
} 


\subsection{Productivity and income}

Given this amount of heterogeneity in the model, it is useful to define the productivity and the wage corresponding to a firm-worker pair. The productivity is given by:

$$
y(h, a, f, x, e)=A_{e} h x \ell(h, a, f, x, e)
$$

where $A_{e}$ is an education-dependent scaling parameter and $\ell() \in[0,1]$ corresponds to the number of hours of work supplied by the individual.

Following (Burdett et al., 2011; Bagger et al., 2014; Blundell et al., 2016), we consider pre-tax hourly wages to be defined by the following rule:

$$
\log (w(h, x, e))=\log \left(A_{e}\right)+\log (x)+\bar{\alpha}_{e} \log (h),
$$

where $A_{e}$ and $\bar{\alpha}_{e}$ are parameters mapping the wage as a function of the productivity variables.

As in Blundell et al. (2016), we compute the net social transfer (welfare less taxes), depending on age, family status, education, and labor force status. We map these revenues into the model's state space by defining $b(a, f, e, j)$ as the net monetary gains derived from all tax and welfare programs. $j=\{u, n\}$ stands for the job status i.e., unemployed $(\mathrm{u})$ or employed $(\mathrm{n})$.

\subsection{Modeling of the EITC}

Our model seeks to capture the major characteristics of the EITC. For simplicity, we denote by $\widetilde{w}=w \ell$ the earned income. Workers can receive the tax credit depending on their earned income ${ }^{6} \widetilde{w}$. Let $\bar{\tau}$ be the basic social security contribution rate. Let $c_{\max }$ be the maximum tax credit. Let $w_{m}$ and $\underline{w}$ be respectively the minimum and the maximum earned income to benefit from the maximum tax credit (the lower and upper bounds of the "plateau" range). Let $\bar{w}$ be the maximum earned income to benefit from the EITC (the upper bound of the "phase-out" range). We denote by $\tau(\widetilde{w}, f)$ the social security contribution tax net of the tax credit. Formally, it may be written:

$$
\tau(\tilde{w}, f)=\underbrace{\bar{\tau} \widetilde{w}}_{\substack{\text { basic } \\ \operatorname{tax}}}-\underbrace{\max \left(\min \left(\frac{\widetilde{w}}{w_{m}(f)}, 1, \frac{\bar{w}(f)-\widetilde{w}}{\bar{w}(f)-\underline{w}(f)}\right), 0\right) c_{\max }(f)}_{\text {EITC }} .
$$

It is worth noting that the parameters depend on the family status, as in the original rule presented in Figure 1. Note that:

- If $\widetilde{w} \in\left[0, w_{m}[\right.$, the EITC increases with earned income.

- If $\widetilde{w} \in\left[w_{m}, \underline{w}\left[\right.\right.$, the EITC does not vary with earned income, and is equal to $c_{\max }$.

- If $\widetilde{w} \in[\underline{w}, \bar{w}[$, the EITC decreases with earned income.

- If $\widetilde{w} \in[\bar{w},+\infty[$, the EITC is zero.

\footnotetext{
${ }^{6}$ According to the regulation, earned income includes labor income, as well as certain disability payments. For EITC recipients, wage and salary income represents on average $95 \%$ of earned income.
} 


\subsection{Matching}

In the spirit of Menzio et al. (2016), we consider directed search over educational attainment $e$, age $a$, and human capital $h$. The number of hires per unit of time in each sub-market is given by the following matching function:

$$
m(h, a, e)=m\left(\int u(h, a, f, e) s(h, a, f, e) d f, v(h, a, e)\right),
$$

where $u(h, a, f, e) \geq 0$ is the mass of unemployed workers, $v(h, a, e)$ denotes the mass of vacancies, and $s(h, a, f, e)$ stands for the endogenous search effort. Note that $u()$ and $s()$ both depend on the family status, while $v()$ does not. Otherwise stated, firms cannot post vacancies targeting a specific family status. The matching function (5) is increasing and concave in its two arguments and exhibits decreasing return to scale. The job finding probability per efficiency unit of worker search $p(h, a, e)$ and the vacancy filling probability $q(h, a, e)$ are defined by:

$$
\begin{aligned}
& p(h, a, e)=m(h, a, e) / \int u(h, a, f, e) s(h, a, f, e) d f, \\
& q(h, a, e)=m(h, a, e) / v(h, a, e) .
\end{aligned}
$$

\subsection{Timing of events}

At the beginning of age $a$, employed individuals decide how many hours of work they supply. Unemployed workers choose their optimal search effort. The matching between vacancies and unemployed workers occurs right after. Then, all workers (employed or unemployed) draw a new family status and human capital level. Unemployed workers finding a new job and existing matches draw a new level of idiosyncratic productivity from two distinct distributions. The unemployed workers may be successfully hired or may return to the unemployment pool. Symmetrically, an employed worker may continue the relation or may separate from the firm. Separations may occur endogenously or exogenously. First, we assume that the worker may quit the job or may be laid off by the firm. This event results from optimal firms' and workers' decisions and is endogenously determined. Second, we assume that workers separate from their employment relationship at the exogenous rate $\delta_{e}$. Figure 5 depicts the timing of events. In the next sections, we describe match acceptance, quit, and layoff decisions. 
Figure 5: TIMING OF EVENTS

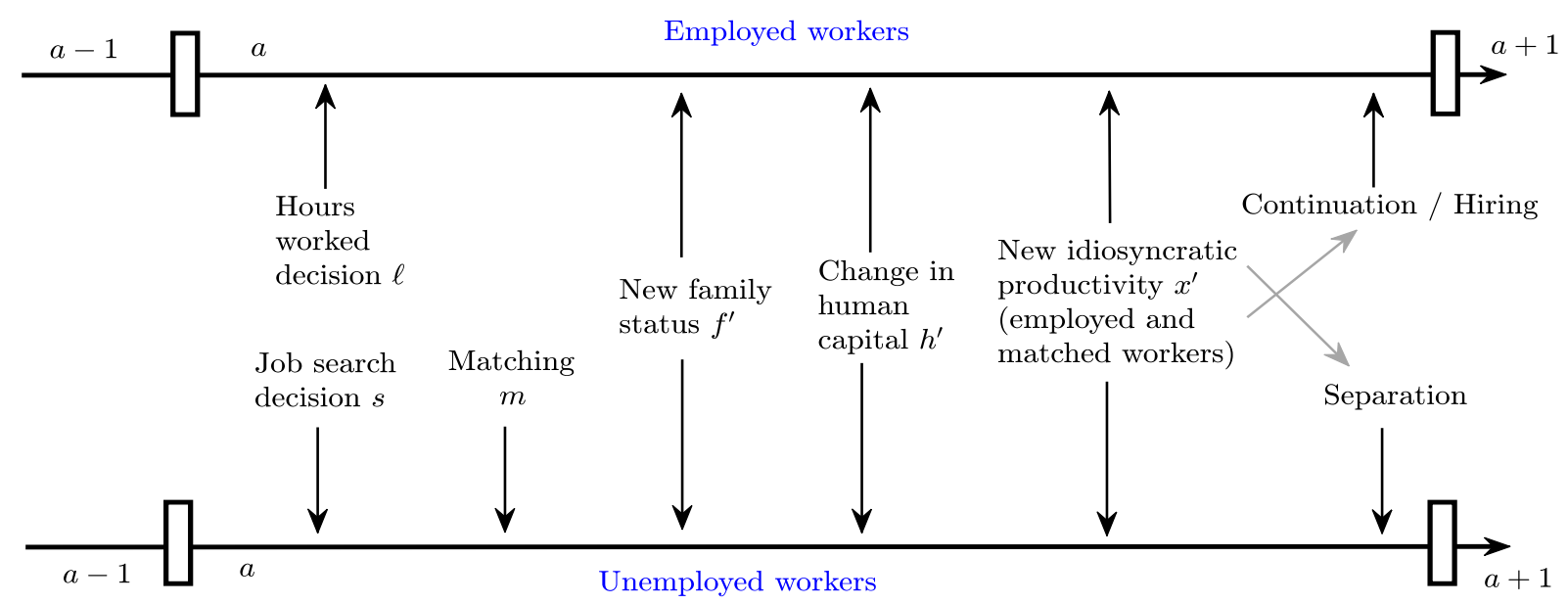

\subsection{Bellman equations}

Optimal continuation and acceptance decisions. For the sake of exposition, we drop subscripts related to the state space $(h, a, f, x, e)$ where unnecessary. We denote by $W$, $U, J$, and $V$ the value functions for an employed worker, an unemployed worker, a filled job, and a vacant job, respectively. The optimal decisions are given by:

$$
\begin{aligned}
\Omega(h, a, f, e) & =\max [W(h, a, f, x, e), U(h, a, f, e)] \\
\Lambda(h, a, f, x, e) & =\max [J(h, a, f, x, e), V(h, a, e)] .
\end{aligned}
$$

For an employed worker, $\Omega$ represents the optimal decision to continue the match. If the value of unemployment exceeds the value of employment, a quit occurs. Otherwise, the relation goes on. For an unemployed worker, $\Omega$ represents the decision to accept or turn down the job offer. Similarly, for a firm with a filled job, $\Lambda$ provides the decision to maintain the employment relation or to layoff the worker. For a firm with an unfilled position, it determines whether a vacant job is transformed into a filled job.

Employed workers. We assume that employed workers choose how many hours they are willing to supply given the statutory constraint imposed by the EITC. The value function for an employed worker writes:

$$
W(h, a, f, x, e)=\begin{aligned}
& \max _{\ell \in \Omega_{\ell}}\left\{w(h, x, e) \ell-\tau(w(h, x, e) \ell)+b(a, f, e, n)-\eta(a, e) \frac{\ell^{1+\phi}}{1+\phi}\right\} \\
& +\beta \sum_{h^{\prime}} \mu_{n}\left(h, h^{\prime}\right) \iint\left[\begin{array}{c}
\left(1-\delta_{e}\right) \Omega\left(h^{\prime}, a^{\prime}, f^{\prime}, x^{\prime}, e\right) \\
+\delta_{e} U\left(h^{\prime}, a^{\prime}, f^{\prime}, e\right)
\end{array}\right] d Z\left(x^{\prime} \mid x\right) d G_{a, e}\left(f^{\prime} \mid f\right) .
\end{aligned}
$$

An employed worker earns $w \ell$, pays taxes net of the EITC $\tau(w \ell)$, and receives net social transfer $b$. The fourth term on the right-hand side corresponds to the disutility from working. $\eta(a, e)$ is a scaling function governing the change in disutility during the life cycle and across education level. Indeed, lower-educated workers are more likely to occupy jobs that are more physically demanding and damaging to their health than skilled workers. As a consequence, the disutility from working may increase with age and differ across educational attainments. $\phi$ represents the inverse of the 
Frisch elasticity. The first-order condition with respect to $\ell$ provides the optimal hours worked decision:

$$
w-w \frac{\partial \tau(w \ell)}{\partial \ell}-\eta(a, e) \ell^{\phi}=0
$$

Given the non-linear nature of the tax function, we solve for the optimal hours worked decision $\ell$ numerically. The last term on the right-hand-side gives the expected value of employment given the change in human capital, age, idiosyncratic productivity, and family status.

Unemployed workers. An unemployed worker receives an income $b(a, f, e, u)$. She decides her optimal search effort $s$ given the search cost function $k(s)$, with $k^{\prime}(s)>0$ and $k^{\prime \prime}(s) \geq 0$, and the expected gain of searching. The value function may be written:

$$
U(h, a, f, e)=\max _{s}\left\{\iint\left[\begin{array}{c}
b(a, f, e, u)-k(s)+\beta \sum_{h^{\prime}} \mu_{u}\left(h, h^{\prime}\right) \times \\
1-p(h, a, e) s) U\left(h^{\prime}, a^{\prime}, f^{\prime}, e\right) \\
\left.+p(h, a, e) s \Omega\left(h^{\prime}, a^{\prime}, f^{\prime}, e\right)\right)
\end{array}\right] d Z_{0}\left(x^{\prime}\right) d G_{a, e}\left(f^{\prime} \mid f\right)\right\}
$$

An unemployed worker is matched with a vacant job at the rate $p \times s$ and decides whether to accept or turn down the offer. Note that as long as she remains unemployed, her human capital is likely to depreciate with probability $\psi_{u}$. The first-order condition with respect to $s$ provides the optimal search decision:

$$
k^{\prime}(s)=p \beta \sum_{h^{\prime}} \mu_{u}\left(h, h^{\prime}\right) \int \Omega\left(h^{\prime}, a^{\prime}, f^{\prime}, x^{\prime}, e, t^{\prime}\right)-U\left(h^{\prime}, a^{\prime}, f^{\prime}, e, t^{\prime}\right) d Z_{0}\left(x^{\prime}\right) d G_{a, e}\left(f^{\prime} \mid f\right) .
$$

The above condition states that the marginal cost of searching a job equates the expected marginal value from an employment relationship.

Filled job. The value function for a firm with a filled job is given by:

$$
J(h, a, f, x, e)=\max \left\{\begin{array}{l}
y(h, a, f, x, e)-w(h, x, e) \ell(h, a, f, x, e)+\beta \sum_{h^{\prime}} \mu_{n}\left(h, h^{\prime}\right) \times \\
0,\left(1-\delta_{e}\right) \iint \Lambda\left(h^{\prime}, a^{\prime}, f^{\prime}, x^{\prime}, e\right) d Z\left(x^{\prime} \mid x\right) d G_{a, e}\left(f^{\prime} \mid f\right)
\end{array}\right\} .
$$

A firm with a filled job receives a flow of profit equal to the productivity minus the labor costs. For the employed worker, the human capital may increase every period, provided that the match continues. Note that the value of a filled job does depend on the family status $f$, as the level of hours worked is chosen by the employed worker to maximize her present utility.

Vacant job. Each firm is free to open a vacant job directed toward a worker of educational attainment $e$, age $a$, and human capital $h$. To do so, the firm incurs a vacancy cost that depends on the education level $c_{e}$. Formally, the Bellman equation associated with a vacant job may be written:

$$
V(h, a, e)=-c_{e}+\beta\left[\begin{array}{l}
q(h, a, e) \iint_{0} \pi\left(h, a, f^{\prime}, e\right) \Lambda\left(h, a^{\prime}, f^{\prime}, x^{\prime}, e\right) d Z_{0}\left(x^{\prime}\right) d f^{\prime} \\
+(1-q(h, a, e)) \max _{h, a, e} V(h, a, e)
\end{array}\right],
$$


where $\pi(h, a, f, e)$ is the proportion of unemployed workers with family status $f$ :

$$
\pi(h, a, f, e)=\frac{u(h, a, f, e)}{\int u(h, a, f, e) d f} .
$$

Note that the value of a vacant job is independent of family status. Before the match occurs, the family status of the unemployed is unknown. Firms just know the distribution of unemployed workers across family status. In case of a successful match, the family status of the worker is revealed. The expected gain from posting a vacancy is equal to the sum of job values $\Lambda$ weighted by the number of unemployed workers in each family status category $\pi(h, a, f, e)$.

\subsection{Job creation and job destruction}

Firms enter the labor market and open vacancy positions until the expected market opportunities are exhausted, that is, when $V(h, a, e)=0$. Plugging this condition into the value of a vacancy (Equation (15)) leads to the following job creation condition.

$$
\frac{c_{e}}{q}=\beta \iint \pi\left(h, a, f^{\prime}, e\right) \Lambda\left(h, a^{\prime}, f^{\prime}, x^{\prime}, e\right) d Z_{0}\left(x^{\prime}\right) d f^{\prime}
$$

We define $\mathbb{1}_{\varrho}\{h, a, f, x, e\}$, an indicator function defining the optimal separation decisions for a firm $(\varrho=$ firm $)$ and for a worker $(\varrho=$ worker $)$, thus:

$\mathbb{1}_{\varrho}\{h, a, f, x, e\}=\left\{\begin{array}{lll}0 & \text { if } & \varrho=\text { firm and } \quad J(h, a, f, x, e) \leq 0 \\ 1 & \text { otherwise } & \varrho=\text { worker and } W(h, a, f, x, e) \leq U(h, a, f, e)\end{array}\right.$

The above expression provides the private optimal strategy for the firm and the worker separately. Since there is no bargaining over the surplus to set wages or hours in our model, this decision is not necessarily mutually beneficial for both parties. The effective optimal separation and match acceptance decision is the product of the two, that is:

$$
\mathbb{1}\{h, a, f, x, e\}=\mathbb{1}_{\text {firm }}\{h, a, f, x, e\} \times \mathbb{1}_{\text {worker }}\{h, a, f, x, e\} .
$$

If one of the two parties in the match decides to end the employment relation $(\mathbb{1}\{h, a, f, x, e\}=$ 0 ), the match is destroyed. Phrased differently, inefficient separations might occur in equilibrium.

\subsection{Education choice}

We borrow from Chéron and Terriau (2018) and Albertini and Terriau (2019) their modeling of educational choice. Before entering the labor market, individuals choose their educational attainment $e \in \Omega_{e}, \Omega_{e}=\left\{e_{1}, e_{2}\right\}$, with $e_{1}$ : less than high school and $e_{2}$ : high school and over. The optimal schooling decision is based on several factors.

1 Each individual is endowed with an ability $\zeta$ defining her aptitude to perform studies. We assume that $\zeta$ has a discrete support $[\zeta, \bar{\zeta}]$ and is distributed according to a Pareto distribution $P($.$) .$ 
2 The cost of education includes the tuition fees equal to $Y_{e}$, which depends directly on the educational attainment; and a cost of effort $\Phi(\zeta)$ related to the individual's ability to perform studies. We assume that the function $\Phi($.$) is continuous, de-$ creasing and convex, and twice differentiable. The total cost of doing studies expressed in monetary term is then:

$$
\kappa(e, \zeta)=\mathrm{Y}_{e}+\Phi(\zeta)
$$

3 The duration of an educational attainment $e$ is $d_{e}$ with $d_{1}<d_{2}$. The duration of the studies has a direct incidence on the schooling decision, as it determines the opportunity cost and serves as a discount rate for future payoff.

4 After their educational attainment, individuals enter the labor market as unemployed. The life-cycle expected payoff is a key statistic on which the educational choice is made. This value can directly be determined by the Bellman equation of an unemployed worker:

$$
U\left(h_{1}, a_{0}+d_{e}, f_{1}, e, t\right)
$$

Note that the level of human capital $h$ is the lowest $\left(h_{1}\right)$ as the individual has no experience, and the age at which she enters the labor market $a_{0}+d_{e}$ depends on the duration of the study. We assume that the family status considered is $f_{1}$ (no child) for simplicity.

We impose the condition $d_{1}=0$ such that low-skilled workers enter the labor market at age $a_{0}$. The optimal educational decision is the solution of the following program:

$$
\begin{aligned}
e_{\zeta}^{\star} & =\underset{e \in \Omega_{e}}{\arg \max } \Pi(\zeta, e, t) \\
\text { with } \Pi(\zeta, e, t) & =\mathbb{1}_{e \neq e_{1}} \sum_{a=a_{0}}^{a_{0}+d_{e}} \beta^{a-1}(-\kappa(e, \zeta))+\beta^{a_{0}+d_{e}} U\left(h_{1}, a_{0}+d_{e}, f_{1}, e, t\right),
\end{aligned}
$$

where $\mathbb{1}_{e \neq e_{1}}$ is an indicator variable taking the value one if educational attainment is $e=e_{2}$ (high school or higher). Individuals choose to pursue schooling until the marginal gain of an extra degree of education becomes lower than the marginal cost associated with the additional degree.

The proportion of individuals in each educational program is given by:

$$
\begin{aligned}
\Gamma_{e_{2}} & =\int \mathbb{1}\left\{\Pi\left(\zeta, e_{2}, t\right)>\Pi\left(\zeta, e_{1}, t\right)\right\} d P(\zeta) \\
\text { and } \Gamma_{e_{1}} & =1-\Gamma_{e_{2}}
\end{aligned}
$$

It should be noted that $\Gamma_{e_{i}}$ determines the distribution of new entries in the labor force but not in the labor market; the latter depends on the duration of studies $d_{e}$.

\subsection{Laws of motion}

The model is characterized by a continuum of individuals of mass one. Each individual is either employed or unemployed. Students are counted as unemployed. The evolution of each type of worker is described by a law of motion. We denote by $n(h, a, f, x, e)$ 
the stock of employed workers and by $u(h, a, f, e)$ the stock of unemployed workers. Denote by $\bar{a}=a-1$, the laws of motion are given by:

$$
\begin{aligned}
n(h, a, f, x, e)= & \mathbb{1}\{h, \bar{a}, f, x, e\}\left[\left(1-\delta_{e}\right) \sum_{h^{\prime}} \mu_{n}\left(h^{\prime}, h\right) \iint n\left(h^{\prime}, \bar{a}, f^{\prime}, x^{\prime}, e\right) d Z\left(x \mid x^{\prime}\right) d G_{\bar{a}, e}\left(f \mid f^{\prime}\right)\right. \\
& \left.\quad+z_{0}(x) p(h, \bar{a}, e) s(h, \bar{a}, f, e) \sum_{h^{\prime}} \mu_{u}\left(h^{\prime}, h\right) \int u\left(h^{\prime}, \bar{a}, f^{\prime}, e\right) d G_{\bar{a}, e}\left(f \mid f^{\prime}\right)\right] \\
u(h, a, f, e)= & \sum_{h^{\prime}} \mu_{h}\left(h^{\prime}, h\right) \iint n\left(h^{\prime}, \bar{a}, f^{\prime}, x^{\prime}, e\right)\left[\begin{array}{c}
\left(1-\delta_{e}\right)(1-\mathbb{1}\{h, a, f, x, e\}) \\
+\delta_{e} \mathbb{1}\{h, a, f, x, e\}
\end{array}\right] d Z\left(x \mid x^{\prime}\right) d G_{\bar{a}, e}\left(f \mid f^{\prime}\right) \\
& +\sum_{h^{\prime}} \mu_{u}\left(h^{\prime}, h\right) \int u\left(h^{\prime}, \bar{a}_{,}, f^{\prime}, e\right)\left(1-p\left(h^{\prime}, \bar{a}, f^{\prime}\right) s\left(h^{\prime}, \bar{a}, f^{\prime}, e\right) \int \mathbb{1}\left\{h, a, f, x^{\prime}, e\right\} d Z_{0}\left(x^{\prime}\right)\right) d G_{\bar{a}, e}\left(f \mid f^{\prime}\right)
\end{aligned}
$$

Given that each worker leaves the labor force at age $a_{A}$, each age category has the same weight in the total labor force. Consequently, at each period $a$, the oldest generation is replaced by the new generation at rate $1 /\left(a_{A}-a_{0}\right)$. A fraction $\Gamma_{e_{1}}$ searches for a job in period $a_{0}+d_{e_{1}}$, while the remainder starts searching in period $a_{0}+d_{e_{2}}$. All individuals performing studies are considered unemployed. The initial conditions are given by:

$$
\begin{aligned}
u(h, a, f, e) & =\frac{\Gamma_{e}}{a_{A}-a_{0}} \quad \forall a \leq a_{0}+d_{e}, h=h_{1}, f=f_{1}, \\
n(h, a, f, x, e) & =0 \quad \forall a \leq a_{0}+d_{e} .
\end{aligned}
$$

\subsection{Government budget}

The government collects taxes from labor, makes transfers, and funds education. We distinguish two costs related to education: (1) $C_{p}$ : the public cost of education, which corresponds to the salary of teachers, public infrastructure, and some running costs.

(2) $C_{s}$ : the educational grant given to students. The fiscal surplus $F S(t)$ is then:

$$
\begin{aligned}
F S= & \sum_{e} \sum_{h} \sum_{a}\left[\int n(h, a, f, x, e)[\tau(w(h, x, e) \ell(h, a, f, e))-b(a, f, e, n)] d x-u(h, a, f, e) b(a, f, e, u)\right] d f \\
& -\left(C_{p}+C_{S}\right) \sum_{e} \sum_{h} \sum_{a=a_{0}}^{a_{0}+d_{2}} \int u(h, a, f, e) d f
\end{aligned}
$$

The government budget is balanced with lump-sum transfers $T_{t}$ :

$$
T_{t}=F S_{t}
$$

\subsection{Definition of the equilibrium}

DEFINITION 1. Given exogenous processes for human capital h, age a, family status $f$, and idiosyncratic productivity $x$; and given a terminal condition for the value function $J, V, W, U=$ 0 , and initial conditions for employment $(n)$ and unemployment $(n)$, the equilibrium is a list of (i) quantities $m(h, a, e), p(h, a, e), q(h, a, e)$, and $v(h, a, e)$; (ii) prices $w(h, a, x, e)$ and $y(h, a, x, f, e)$; (iii) value functions $J(h, a, f, x, e), V(h, a, e), W(h, a, f, x, e)$, and $U(h, a, f, e)$; (iv) optimal decision $\ell(h, a, f, x, e)$ and $s(h, a, f, e)$; (v) optimal educational decisions $e_{\zeta}^{\star}$; (vi) stationary distributions of workers across skills $\Gamma_{e}$; (vii) stationary distributions of employment $n(h, a, f, x, e)$ and unemployment $u(h, a, f, e)$; and (viii) fiscal surplus FS and lump-sum transfer $T_{t}$ satisfying the following conditions: 
(i) $m(h, a, e), q(h, a, e), p(h, a, e)$, and $v(e, h, a, t)$ are the solutions of the matching function (5), the vacancy filling rate (7), the job finding rate (6), and the job creation condition (17), respectively;

(ii) Prices $y(h, a, x, f, e)$ and $w(h, a, x, e)$ satisfy equations (2) and (3);

(iii) Value functions $J(h, a, f, x, e), V(h, a, e), W(h, a, f, x, e)$, and $U(h, a, f, e)$ are solutions of the system that combines (10), (12), (14) and(15);

(iv) The optimal hours worked decision solves (11);

(v) $e_{\zeta}^{\star}$ solves the educational choice program (19);

(vi) $\Gamma_{e}$ satisfies the stationary distribution (20);

(vii) The distributions $n(h, a, f, x, e)$ and $u(h, a, f, e)$ solve the law of motion described by (21) and (22); and

(viii) FS and $T_{t}$ satisfy the government budget defined by (25) and (26).

\section{$5 \quad$ Numerical analysis}

\subsection{Functional forms}

- Human capital is given by the following function:

$$
h_{i}=\left(\frac{h_{H}-h_{1}}{H-1} \times i\right)^{\gamma_{e}}, i=1, \ldots, H .
$$

The parameter $\left.\gamma_{e} \in\right] 0,1[$ shapes the curvature of the human capital.

- We consider a Cobb-Douglas matching function:

$$
m(u, v)=\chi u^{v} v^{1-v}
$$

where $\chi$ represent the matching efficiency parameter and $v$ the elasticity of hirings with respect to unemployment.

- The search cost function takes the following form:

$$
k(s)=\frac{k_{0}}{1+\xi}\left((1-s)^{-(1+\xi)}-1\right)-k_{0} s,
$$

where $k_{0}$ and $\xi$ are parameters governing the level and the curvature of the search intensity function. This function ensures that the search intensity level lies between 0 and 1 . We therefore define the search intensity as the fraction of time devoted to search.

- The education cost function is defined as:

$$
\Phi(\zeta)=\phi_{0} \zeta^{\phi_{1}}
$$

where $\phi_{0}$ and $\phi_{1}$ are parameters determining the size of and the slope of the cost function, respectively. 
- Abilities $x$ are distributed according to the Pareto distribution over the support $[\underline{\zeta}, \bar{\zeta}]:$

$$
P(\zeta)=\frac{1-(\underline{\zeta} / \zeta)^{d}}{1-(\underline{\zeta} / \bar{\zeta}) d^{\prime}}
$$

- Labor disutility takes the following functional form:

$$
\eta(a, e)= \begin{cases}\bar{\eta}_{e} & \text { if } a<a^{\star} \\ \bar{\eta}_{e}+\rho_{e}\left(a-a^{\star}\right)^{2} & \text { otherwise }\end{cases}
$$

$\bar{\eta}_{e}$ scales disutility across jobs with different educational attainment. ${ }^{7} a^{\star}$ is the age above which the disutility increases with age at rate $\rho_{e}$.

\subsection{Calibration and estimation}

We calibrate some parameters using external information and use a minimization procedure to estimate the remaining parameters. We provide an online appendix describing in detail the solution method and the estimation procedure.

\subsubsection{Parameter set externally}

Labor market and heterogeneities. We consider monthly frequencies and a life-cycle horizon of 54 years with $a_{0}=16$ and $a_{A}=69$. The discount factor is set to 0.9966, giving an annual real interest rate of about $4 \%$. We consider five human capital levels $(H=5)$. We set the bounds defining the range of human capital level $h_{1}=1$ and $h_{H}=5$. The family status $f$ evolves according to a four-state Markov process. The transition matrix is age- and education-dependent:

$$
g_{a, e}=\left[\begin{array}{cccc}
g_{a, e, 1,1} & g_{a, e, 1,2} & \ldots & g_{a, e, 1,4} \\
g_{a, e, 2,1} & g_{a, e, 2,2} & \ldots & g_{a, e, 2,4} \\
\vdots & \ldots & \ddots & \vdots \\
g_{a, e, 4,1} & \ldots & \ldots & g_{a, e, 4,4}
\end{array}\right]
$$

The transition probabilities are estimated using the CPS and are thus exogenous. The estimation procedure as well as the path of the transition probabilities are displayed in Appendix $\mathrm{H}$.

In line with Petrongolo and Pissarides (2001), we consider the elasticity of the matching function with respect to unemployment equal to 0.5 . The idiosyncratic productivity $x$ evolves according to an order-one autoregressive process with persistence $\rho_{x}$ and standard deviation $\sigma_{x}$, estimated thereafter. The process is discretized using the Rouwenhorst method with three grid points. New matches draw an idiosyncratic productivity from the unconditional distribution $Z_{0}\left(x^{\prime}\right)$, considered uniform. The exogenous separation $\delta_{e}$ is set to the mean level observed from the CPS data.

\footnotetext{
${ }^{7}$ Our functional form is close to the one used by Iskhakov and Keane (2020).
} 
Education. In line with Chéron and Terriau (2018), we consider that abilities for education are distributed according to a truncated Pareto distribution over the support $[1,2]$ with curvature parameter $d=1 .^{8}$ As in Donovan and Herrington (2019), the public and private costs of education (per year and per student) are taken from the Digest of Education Statistics 2018 (see Appendix E for further details). They represent, respectively, $14 \%$ and $33 \%$ of the median earned income. Thus, $C_{p}$ amounts to 0.25 while $C_{s}$ is equal to 0.59 . The estimated average duration of the educational attainment $e_{2}$ (high school and over) is 3 years, in which case $d_{1}=0$ and $d_{2}=36$ months.

The parameters of the educational cost function, $\phi_{0}$ and $\phi_{1}$, are pinned down to match: (1) the proportion of skilled and unskilled workers, and (2) the elasticity of this proportion with respect to the generosity of the EITC program. For (1), the observed proportion of skilled workers is $89.6 \%$. For (2), we use the result from Table 2. Doubling $c_{\text {max }}$ involves a decrease in the proportion of skilled workers by 7.20 percentage points. We solve and simulate the model for a value of $c_{\max }$ and for a value of $c_{\max }^{\prime}=2 c_{\max }$. We then solve for the values of $\phi_{0}$ and $\phi_{1}$ that match the two targets.

Labor market institutions. In order to calibrate the EITC tax schedule $\left(w_{m}(f), \underline{w}(f)\right.$, $\left.\bar{w}(f), c_{\max }(f)\right)$, we use the values displayed in Appendix A in 2018 for each family status and each phase of the EITC. The net social transfer by age, family status, education, and job status $b(a, f, e, j)$ is estimated using the CPS data by family status, age, educational attainment, and job status, and is reported in Appendix G. All these values are expressed in monetary terms. To set the values in the model, we express them as fractions of the observed median earned income $(\$ 37,343)$. For an initial value of the median earned income in the model, we compute initial guesses for the tax schedule parameters and the life-cycle series of net social transfer. We then solve the model and calculate the median earned income. We adjust the tax schedule and the net social transfer using the fraction calculated above and repeat this procedure until convergence. All the calibrated parameters are reported in Table 3.

\footnotetext{
${ }^{8}$ We impose these values for the Pareto distribution but estimate the educational cost function. Changing the support does not affect the quantitative implications of the model since it simply scales the range of abilities.
} 
Table 3: CALIBRATED PARAMETERS

\begin{tabular}{|c|c|c|c|c|}
\hline Parameter & Symbol & \multicolumn{3}{|c|}{ Value } \\
\hline Discount factor & $\beta$ & \multicolumn{3}{|c|}{0.9966} \\
\hline Expected entry age - unskilled & a_0 & \multicolumn{3}{|c|}{16} \\
\hline Expected entry age - skilled & $a \_0+d \_2$ & \multicolumn{3}{|c|}{19} \\
\hline Final age & $a_{A}$ & \multicolumn{3}{|c|}{69} \\
\hline Age of increasing disutility of work & $a^{*}$ & \multicolumn{3}{|c|}{50} \\
\hline Human capital range & {$\left[h_{1}, h_{H}\right]$} & \multicolumn{3}{|c|}{$[1.0,5.0]$} \\
\hline Matching function elasticity & $v$ & \multicolumn{3}{|c|}{0.5} \\
\hline Separation rate - unskilled & $\delta_{1}$ & \multicolumn{3}{|c|}{0.06} \\
\hline Separation rate - skilled & $\delta_{2}$ & \multicolumn{3}{|c|}{0.03} \\
\hline Support for the Pareto distribution & {$[\zeta, \bar{\zeta}]$} & \multicolumn{3}{|c|}{$[1.0,2.0]$} \\
\hline Shape of the Pareto distribution & $d$ & \multicolumn{3}{|c|}{1.0} \\
\hline Public cost of education & $C_{p}$ & \multicolumn{3}{|c|}{0.25} \\
\hline Private cost of education & $C_{s}^{p}$ & \multicolumn{3}{|c|}{0.59} \\
\hline Education cost function scale & $\phi_{0}$ & \multicolumn{3}{|c|}{2.52} \\
\hline Education cost function elasticity & $\phi_{1}$ & \multicolumn{3}{|c|}{-1.13} \\
\hline EITC family status & $\mathrm{f}$ & $\mathbf{S}$ & $1 \mathrm{C} \quad 2 \mathrm{C}$ & $3 \mathrm{C}+$ \\
\hline Phase 1 limit & $w_{m}(f)$ & 0.32 & $0.48 \quad 0.68$ & 0.68 \\
\hline Phase 2 limit & $\underline{w}(f)$ & 0.40 & 0.890 .89 & 0.89 \\
\hline Phase 3 limit & $\overline{\bar{w}}(f)$ & 0.73 & $1.92 \quad 2.18$ & 2.34 \\
\hline EITC maximum tax credit & $c_{\max }(f)$ & 0.02 & $0.16 \quad 0.27$ & 0.31 \\
\hline
\end{tabular}

Note: EITC family status are: single (S), one child (1C), two children (2C), three children and more (3C+).

\subsubsection{Parameter set internally}

The remaining parameters are estimated using a simulated method of moments similar to Albertini and Terriau (2019). We have seven parameters that depend on educational attainment and six parameters that are common across the skill groups. We thus have 20 parameters to estimate. The set of structural parameters is given by:

$$
\Theta=\left\{\gamma_{e}, \bar{\alpha}_{e}, \chi_{e}, c_{e}, A_{e}, \bar{\eta}_{e}, \rho_{e}, \psi_{n}, \psi_{u}, k_{0}, \xi, \rho_{x}, \sigma_{x}\right\}
$$

Our goal is to reproduce the following life-cycle series: (i) the employment rate by educational attainment, (ii) the hours worked by educational attainment, (iii) the earned income deciles D2, D4, D6, and D8, and (iv) the proportion of employed workers in each phase of the EITC (phase-in, plateau, phase-out). While the model is simulated over a life cycle starting at age 16 and finishing at age 69, we target the series (i)-(iii) over the range 20-65 in order to avoid erratic movements in the series due to few observations on the extreme sides of the age spectrum. We then have $I=11$ life cycle series observed at monthly frequencies on a 46-year window involving 6072 moments. We denote by $\left\{\boldsymbol{Y}_{1, a}^{d}, \boldsymbol{Y}_{2, a}^{d}, \ldots, \boldsymbol{Y}_{L, a}^{d}\right\}_{a=20}^{65}$ the set of life cycle series $l=1, \ldots, L$ calculated from the CPS data.

We use a root finding procedure to obtain the parameters that make the moments from the model as close as possible to their empirical counterpart. Formally, the opti- 
mization problem is:

$$
\hat{\Theta}=\underset{\Theta}{\arg \min } \sum_{a=a_{1}}^{a_{A}} \sum_{l=1}^{L} \frac{\left.\| \boldsymbol{Y}_{l, a}^{d}-\boldsymbol{Y}_{l, a}^{m}(\Theta)\right) \|}{\boldsymbol{Y}_{l, a}^{d}}
$$

where $Y_{i, t}^{m}(\Theta)$ are the simulated life-cycle series from the model. We use an adaptive grid to solve the problem (27). ${ }^{9}$ It consists of constructing a wide multidimensional grid covering the space of the parameter values using low-discrepancy grid techniques and refining the grid at each iteration around the values most likely to match the target.

\subsubsection{Estimation results}

Does the model capture the main features of the data? Table 4 summarizes the parameters that are estimated. Figures 6 to 8 show the life-cycle profiles of the hourly wage, hours worked, employment rate, and earned income distribution.

The estimation involves a higher curvature of human capital for skilled workers, implying a steeper wage growth over the life cycle. The TFP is higher for skilled workers by nearly $17 \%$, while at the same time their vacancy posting cost is higher by $60 \%$ and their matching efficiency parameters are nearly the same. The result is a job-finding rate that increases with education rate. The scale parameters for labor disutility are almost equal for both skilled and unskilled workers, but the labor disutility curvature for the former is five times greater than for the latter. For both workers, human capital accumulation rate is more than seven times lower than depreciation, meaning that a worker needs more than seven years of employment to compensate for one year in unemployment on average. Finally, the estimation calls for a large standard deviation of the idiosyncratic productivity shock in order to replicate the wage dispersion observed in the U.S.

Figure 6 displays the average hourly wage, the hours worked, and the employment rate for skilled and unskilled workers. In panel (a), the observed hourly wage rate is nicely replicated despite being not targeted by the estimation procedure, which confirms the goodness of fit. The model matches the important increase in hourly wages for skilled workers at the beginning of their life-cycle and the flattening thereafter. It also replicates the low increase of the unskilled workers' hourly wages. The wage premium between the two groups is nearly null at 20 but reaches 2 at the end of the life-cycle. This feature is mainly due to the difference in the human capital accumulation process.

Figure 7 presents the nine deciles of earned income. It is shown that the model matches the thresholds of the deciles D2, D4, D6, and D8 accurately. It replicates the low inequality between young workers as a result of the low earned income dispersion and the increase afterward, with a peak between ages 30 and 50. The estimation also replicates well the other untargeted deciles, namely, D1, D3, D5, D7, and D9. ${ }^{10}$ Lastly, Figure 8 displays the share of the population in each phase of the EITC. The estimation allows the model to reproduce the data fairly accurately, notably the high share of workers in the phase-out range with respect to the two other ranges. This is an important target, as the response on hours worked critically depends on the range of EITC

\footnotetext{
${ }^{9}$ See the supplementary appendix for details on the solution technique and estimation procedure.

${ }^{10}$ Nonetheless, because we do not include very highly paid workers, the model fails to correctly match the last decile after age 30. This does not represent a major issue in the sense that workers at the top of the income distribution are not concerned with the EITC.
} 
in which the workers stand. Our model is able to capture the proportion of workers in each phase of the EITC schedule as well as the life-cycle dynamics.

Table 4: ESTIMATED PARAMETERS

\begin{tabular}{|c|c|c|c|}
\hline PARAMETER & SYMBOL & UNSKILLED & SKILLED \\
\hline Curvature - human capital & $\gamma$ & 0.55 & 0.76 \\
\hline Curvature - hourly wage & $\bar{\alpha}$ & 0.61 & 0.87 \\
\hline Matching efficiency & $\chi$ & 0.21 & 0.17 \\
\hline Vacancy posting cost & $c$ & 0.43 & 0.68 \\
\hline TFP & $A$ & 0.96 & 1.12 \\
\hline Labor disutility scale & $\bar{\eta}$ & 1.15 & 1.25 \\
\hline Labor disutility curvature (x1000) & $\rho$ & 0.01 & 0.05 \\
\hline & \multicolumn{3}{|c|}{ COMMON } \\
\hline Inverse of the Frisch elasticity & $\phi$ & \multicolumn{2}{|l|}{1.20} \\
\hline Prob. switch human cap. & $\psi_{n}$ & \multicolumn{2}{|l|}{0.03} \\
\hline Prob. switch human cap. & $\psi_{u}$ & \multicolumn{2}{|l|}{0.23} \\
\hline Search cost scale & $k_{0}$ & \multicolumn{2}{|l|}{0.51} \\
\hline Search cost curvature & $\xi$ & \multicolumn{2}{|l|}{0.74} \\
\hline Persistence of idio. prod. & $\rho_{x}$ & \multicolumn{2}{|l|}{0.86} \\
\hline Standard deviation of idio. prod. & $\sigma_{x}$ & \multicolumn{2}{|l|}{0.18} \\
\hline
\end{tabular}


Figure 6: SKILLED VS UNSKILLED

(a) Hourly wage

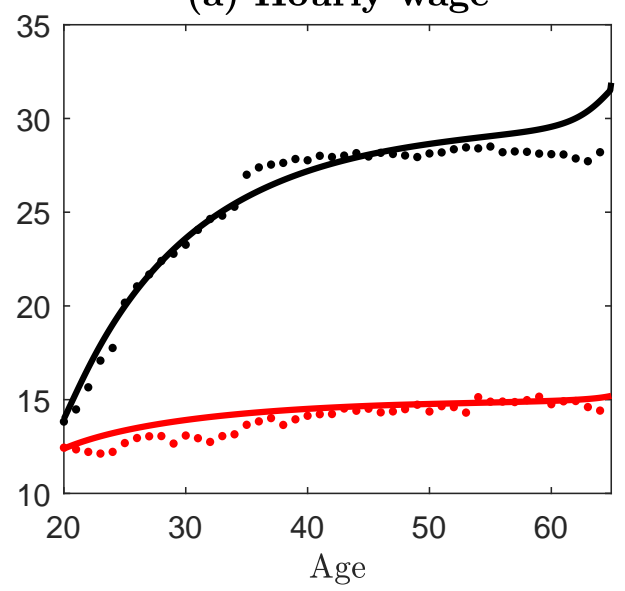

(c) Employment rate

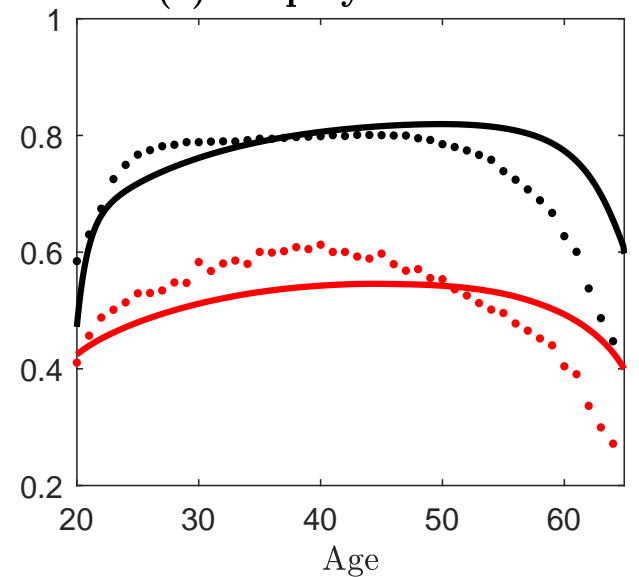

(b) Hours worked

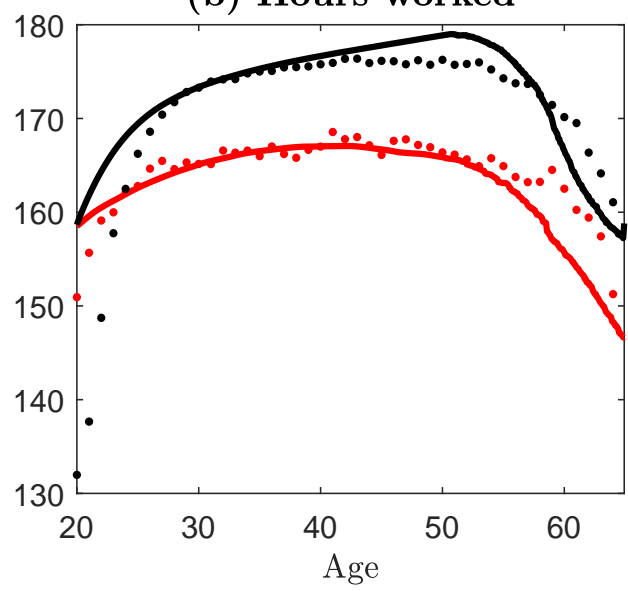

Model: unskilled

- Model: skilled

- Data: unskilled

- Data: skilled

Source: CPS, 2005-2018 (see Appendix F for more details). Note: Monthly hours worked are displayed. 
Figure 7: EARNED INCOME DECILES OVER THE LIFE CYCLE

Source: CPS, 2005-2018. Note: Monthly earned income (hourly wage rate times hours worked) for all employed workers at each age. Values from the model are scaled using the average earned income across all employed workers for comparison purposes. 
Figure 8: PROPORTION OF WORKERS IN EACH PHASE OF THE EITC SCHEDULE
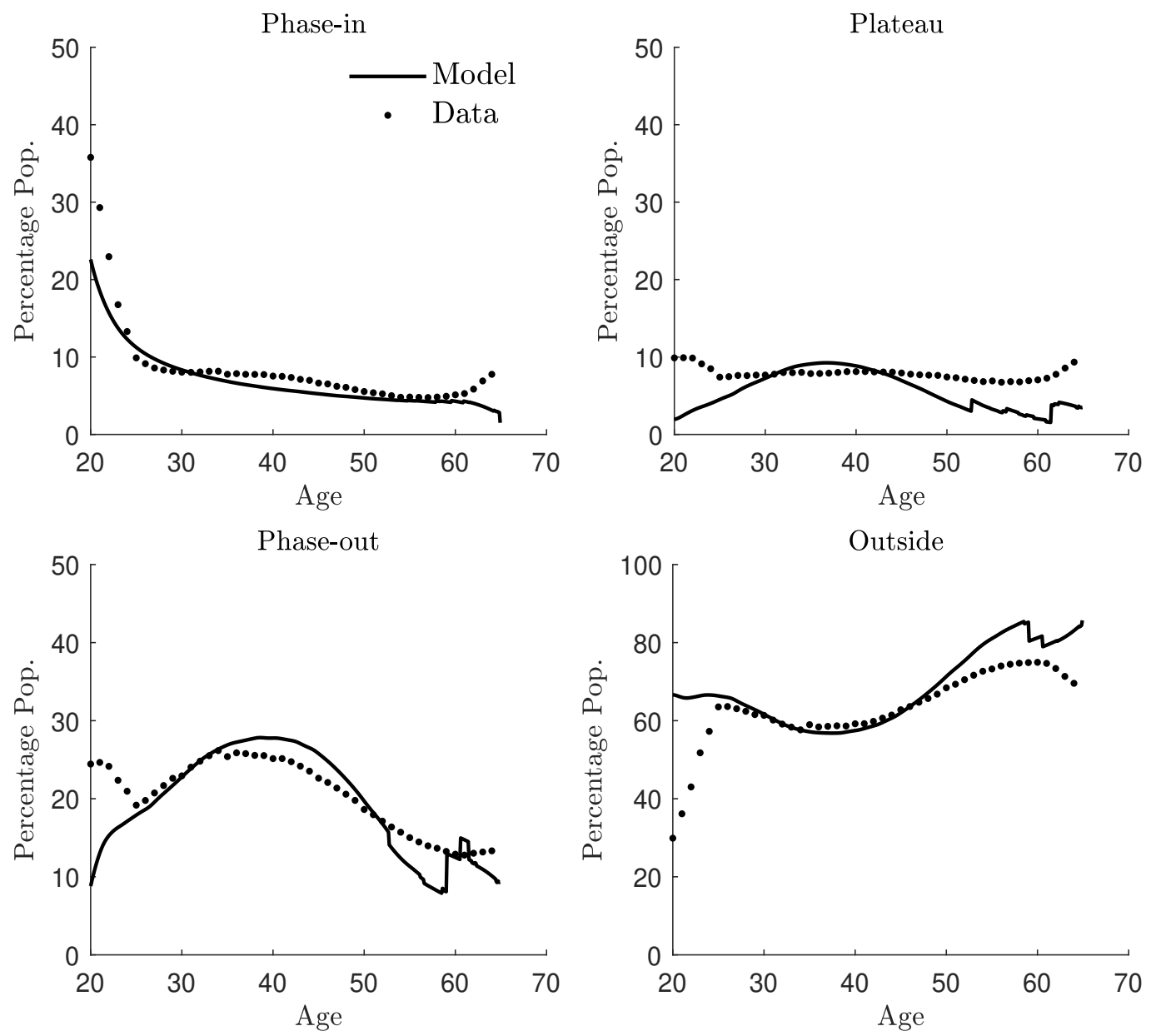

Source: CPS, 2005-2018.

\section{Quantifying the impact of a change in EITC}

We have shown that our model was able to replicate the main features of the U.S. labor market. We now investigate the impact of an increase in EITC on education decisions, life-cycle trajectories, and inequalities. As mentioned above, many states have implemented their own EITC, ranging from 3.5 to $50 \%$ of the federal EITC over the period 2005-2018. Recently, the District of Columbia expanded the EITC to $100 \%$ of the federal credit. ${ }^{11}$ Given the considerable costs associated with EITC, this naturally raises questions about the potential effects of such a reform. If all states followed this strategy (if the current maximum amount of federal EITC was doubled), what would be the effects on education, labor market, and life-cycle earnings?

\footnotetext{
${ }^{11}$ The extension only applies to childless workers.
} 


\subsection{Long-term effects of an increase in EITC}

To answer this question, we run a first experiment simulating the impact of doubling the federal EITC, that is, $c_{\max }^{\prime}=2 c_{\max }$. Table 5 displays the effect of such a reform on hours worked and earnings. To understand the effect on hours worked, it is essential to connect this to the design of EITC (see Figure 1). For workers in the phase-in range, according to our simulations, the substitution effect is much larger than the income effect, so that the EITC provides an incentive to increase hours worked. In the plateau range, the substitution effect disappears, but the income effect is too small to cause average hours worked to fall significantly. In the phase-out range, the EITC acts as an implicit tax: Each additional hour of work reduces the amount of EITC by the phaseout rate. This implicit tax provides a strong incentive to decrease hours worked (Hotz, 2003; Trampe, 2007). Finally, workers just above the eligibility threshold are encouraged to reduce the number of hours worked to benefit from the EITC, while those far away (at the right) are unaffected by the reform. As previously mentioned in the literature (Scholz, 1993; Eissa and Hoynes, 2008; Athreya et al., 2010), the vast majority of EITC recipients are low-skilled workers located in the phase-out range. As a result, the increase in EITC leads to a substantial reduction in average unskilled hours worked. As a considerable section of high-skilled workers are outside the EITC range, doubling EITC has a limited effect on average skilled hours worked.

What is the effect on earnings? As the hourly wage is rigid, the earned income follows the same dynamics as hours worked: It slightly increases in the phase-in range, stays stable in the plateau range, decreases substantially in the phase-out range, and slightly decreases for workers outside the EITC range. One may now wonder what the effect is on income when taking into account tax and transfer systems. We now consider the net income (Earned income + EITC + Net social transfer). For recipients in the phase-in and plateau ranges, the reform translates into a substantial increase in net income of $44 \%$ and $37 \%$, respectively, for unskilled and skilled workers. However, as previously noted, very few workers are located in these ranges. The same occurs in the plateau phase, but because workers do not increase their hours worked following the reform, the net income increases by less, nearly $25 \%$ for both skilled and unskilled. In the phase-out range, the EITC compensates the loss in earned income implied by the reduction of hours, and the net income remains unchanged. 
Table 5: POLICY REFORM: INCREASE IN EITC (1)

\begin{tabular}{|c|c|c|c|c|}
\hline \multirow[t]{3}{*}{ Variables } & \multicolumn{2}{|c|}{ Unskilled } & \multicolumn{2}{|c|}{ Skilled } \\
\hline & EITC & $2 \times$ EITC & EITC & $2 \times$ EITC \\
\hline & \multicolumn{4}{|c|}{ Phase-in } \\
\hline Hours worked & 122.2 & 140.1 & 109.7 & 124.4 \\
\hline Earned income & 652 & 746 & 585 & 664 \\
\hline \multirow[t]{2}{*}{ Net income } & 873 & 1257 & 722 & 993 \\
\hline & \multicolumn{4}{|c|}{ Plateau } \\
\hline Hours worked & 146.2 & 146.6 & 140.7 & 140.7 \\
\hline Earned income & 1210 & 1211 & 1372 & 1373 \\
\hline \multirow[t]{2}{*}{ Net income } & 1572 & 1934 & 1810 & 2250 \\
\hline & \multicolumn{4}{|c|}{ Phase-out } \\
\hline Hours worked & 168.4 & 146.1 & 165.0 & 146.6 \\
\hline Earned income & 2281 & 1971 & 2368 & 2094 \\
\hline \multirow[t]{2}{*}{ Net income } & 2477 & 2483 & 2537 & 2537 \\
\hline & \multicolumn{4}{|c|}{ Outside EITC } \\
\hline Hours worked & 180.4 & 179.9 & 181.6 & 181.4 \\
\hline Earned income & 2794 & 2768 & 4845 & 4828 \\
\hline Net income & 2794 & 2770 & 4845 & 4829 \\
\hline
\end{tabular}

Simulation of an increase in the EITC achieved by an increase in $c_{\max }$ by $100 \%$. We simulate 10000 individuals' life-cycle trajectories and compute the average variables at each phase of the EITC. The comparison is made of individuals with the same educational attainment in the benchmark $\left(c_{\max }\right)$ and the increase in EITC scenario $\left(c_{\max }^{\prime}\right)$. Consequently, we focus on the hours response and not on the composition effect. Monthly values are displayed. Hours worked: average number of hours worked expressed in levels. Earned income: hourly wage rate times hours worked. Net income: earned income + EITC + net social transfer. Earned income and net income are expressed in dollars.

We now consider the effects of EITC on education to quantify the impact of the composition effect, i.e., the change in the proportions of skilled and unskilled workers in the economy. As the two groups have very different labor market outcomes, the total impact of EITC may differ from the impact on each skill group taken in isolation.

Table 6 quantifies the impact of the reform on employment, search intensity, contact rate, and job separation rate at steady state. First, consistent with our estimates, the percentage of low-skilled workers in the economy increases by 7.2 percentage points from $10.4 \%$ to $17.6 \%$. Second, the employment rate of workers who have not completed high school decreases by 1.2 percentage points. Although the EITC provides incentives to search for a job and participate in the labor market, it also encourages workers located in the phase-out range and outside the EITC schedule (the vast majority of workers) to reduce the number of hours worked in order to benefit from the program. As the value of a filled job is increasing with hours worked, low-skilled jobs become on average less profitable for employers, which translates into a reduction in the contact rate. The EITC thus generates two opposite effects: It increases the search intensity but decreases the contact rate. As the latter dominates the former, this results in a decrease in the unskilled employment rate. The labor market of high-skilled 
workers is comparatively much less affected by the reform. This is not surprising, given that the EITC targets low-paid (and as a consequence, low-skilled) workers. As a result, it appears clearly that the aggregate effect on employment comes mainly from low-skilled workers. All in all, the increase in EITC generates a direct effect on employment by decreasing the unskilled employment rate, and a composition effect by increasing the proportion of low-skilled workers (with a relatively lower employment rate) in the economy. Both effects act in the same direction, causing the aggregate employment rate to fall by 2.3 percentage points.

Table 6: Policy REFORM: INCREASE IN EITC (2)

\begin{tabular}{|c|c|c|c|c|c|c|c|c|c|}
\hline \multirow[t]{2}{*}{ Variables } & \multicolumn{3}{|c|}{ Total } & \multicolumn{3}{|c|}{ Unskilled } & \multicolumn{3}{|c|}{ Skilled } \\
\hline & EITC & $2 \times \mathrm{EITC}$ & diff. & EITC & $2 \times \mathrm{EITC}$ & diff. & EITC & $2 \times$ EITC & diff. \\
\hline Education & - & - & - & 10.4 & 17.6 & 7.2 & 89.6 & 82.4 & -7.2 \\
\hline Hours worked & 172.5 & 168.9 & -3.6 & 163.2 & 157.9 & -5.3 & 173.2 & 170.4 & -2.8 \\
\hline Employment & 74.2 & 72.0 & -2.3 & 51.2 & 50.0 & -1.2 & 76.9 & 76.6 & -0.3 \\
\hline Search intensity & 45.6 & 44.5 & -1.1 & 34.9 & 35.9 & 1.0 & 48.2 & 48.5 & 0.2 \\
\hline Contact rate & 18.2 & 17.3 & -0.9 & 15.4 & 14.5 & -0.9 & 18.8 & 18.5 & -0.3 \\
\hline Job separation rate & 2.9 & 3.5 & 0.6 & 6.1 & 6.1 & -0.0 & 3.1 & 3.1 & -0.0 \\
\hline
\end{tabular}

Simulation of an increase in the EITC achieved by and increase in $c_{\max }$ by $100 \%$. Average value are displayed. The contact rate corresponds to $p(\theta)$ in the model (It does not include the search intensity). Columns 'diff.' are the difference in percentage points between the benchmark (EITC) and the alternative scenario $(2 \times$ EITC). For hours worked the differences are expressed in percentage deviation from the benchmark.

\subsection{Transitional dynamics}

The findings presented so far are based on stationary distributions. They represent the state of the economy once all agents have adjusted their education and labor market decisions, and once the youngest generation that has experienced the reform retires from the labor market. Given that individuals enter the labor market at age 20 after their educational choice and retire at 69 , following a fiscal shock, it takes half a century to reach the new steady-state. Steady-state comparisons are useful for assessing the long-term impact of fiscal policy but do not allow an analysis of the short-term effects for people living through this tax reform. In particular, a reform's impact on transitional generations may differ considerably from what we observe in the long run. The impact of the credit is both instantaneous, through its effects on hours worked and earned income, and progressive through the effect on education and human capital accumulation. This raises some issues: How do the main variables behave during the transition? How quickly does the economy converge to the new steady-state? How is each cohort impacted by the reform? To address these issues, we propose to compute the whole transitional dynamics induced by the tax reform in an economy characterized by overlapping cohorts of individuals.

Figure 9 presents the transitional dynamics of employment, hours worked, earned income, and net income. It displays the evolution of each variable from the date of the reform and until the youngest generation that has experienced the reform retires from the labor market, 50 years later. It is important to distinguish instantaneous adjust- 
ments resulting from a revision of the optimal decisions of workers and firms, and progressive adjustments resulting from the change in the composition of employment, i.e., the increase in the proportion of low-skilled workers over time. As previously noted, the increase in EITC mainly impacts unskilled individuals. We observe that unskilled hours worked (and to a lesser extent, skilled hours worked) immediately drop at the time of the reform and then stay relatively stable over time. As relatively less educated new generations enter the labor market and replace the oldest generations, we observe a slight decline in total hours over time. Earned income follows the same dynamics. Panel (d) shows that the net income of the unskilled instantaneously jumps following the reform; the EITC more than compensates the fall in earned incomes due to the fall in hours worked. It slightly decreases thereafter as the earned income decreases.

We observe an immediate drop in employment, reflecting instantaneous adjustments, and a continued decrease in the total employment rate during the 50 years following the reform's implementation. The full effect on low-skilled employment is perceptible after 30 years, while it takes half a century for total employment to fully adjust (due to the composition effect implied by the fall in education rate). 
Figure 9: TRANSITIONAL DYNAMICS

All series are averaged over the life cycle (age 20 to 65). EITC doubles in period 0. It takes around 50 years for the variables to adjust to the new equilibrium. Earned income (c): hourly wage rate times hours worked. Net income (d): earned income + EITC + net social transfer.

Finally, it is important to determine the effect of the change in EITC on intergenerational inequality. Figure 10 displays the impact of the reform for five cohorts, along with their life cycles. More precisely, it illustrates how much an agent would gain/lose, in terms of income, compared to the no-reform scenario depending on the education level and the age at the time of the reform. Consistent with our previous findings, skilled workers are almost unaffected by the reform. Consequently, the following comments will focus on low-skilled workers.

First, as the vast majority of workers are concentrated in the phase-out range or outside the EITC, the increase in EITC provides, on average and for any cohort, an incentive to decrease hours worked. As the EITC increases with the number of children (see Figure 1), and as the number of children reaches its maximum at age 40 (see Appendix H), middle-aged workers are particularly impacted by the reform. At age 40, 
the unskilled suffer from a reduction in hours worked (earned income) of $4.5 \%(6 \%)$, while the skilled workers see their hours worked and earned income both fall by $3 \%$. We notice that the youngest generations are more impacted by the reform since they suffer from the degradation of the labor market situation over their entire life-cycle, and are affected through human capital accumulation, labor market trajectories, and life-cycle earnings.

Figure 10: COHORT DYNAMICS (1)
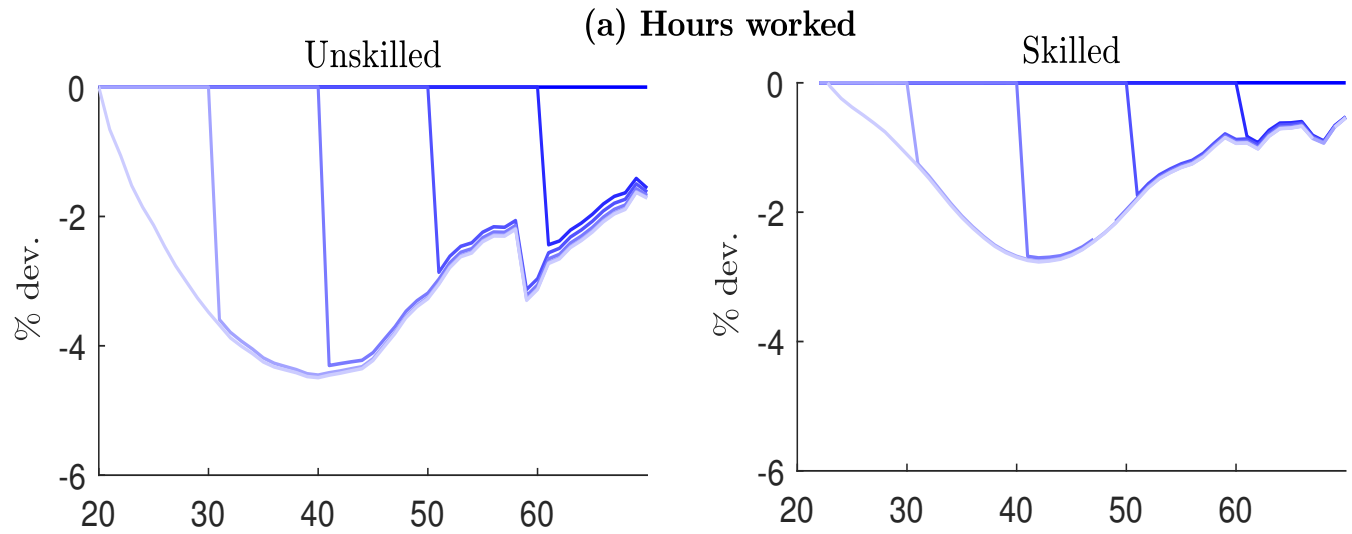

(b) Earned income
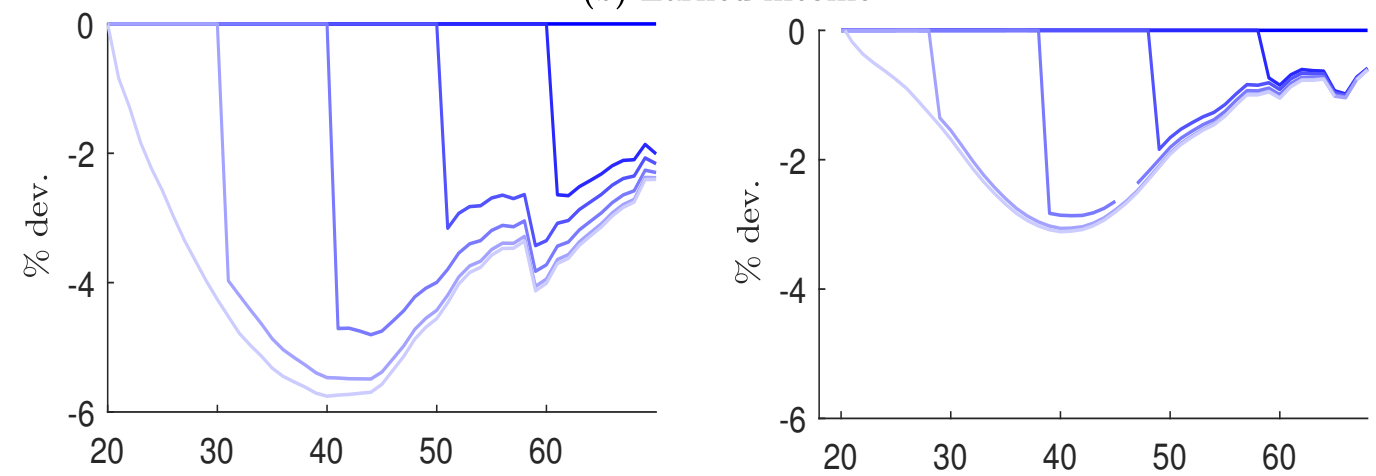

(c) Net income
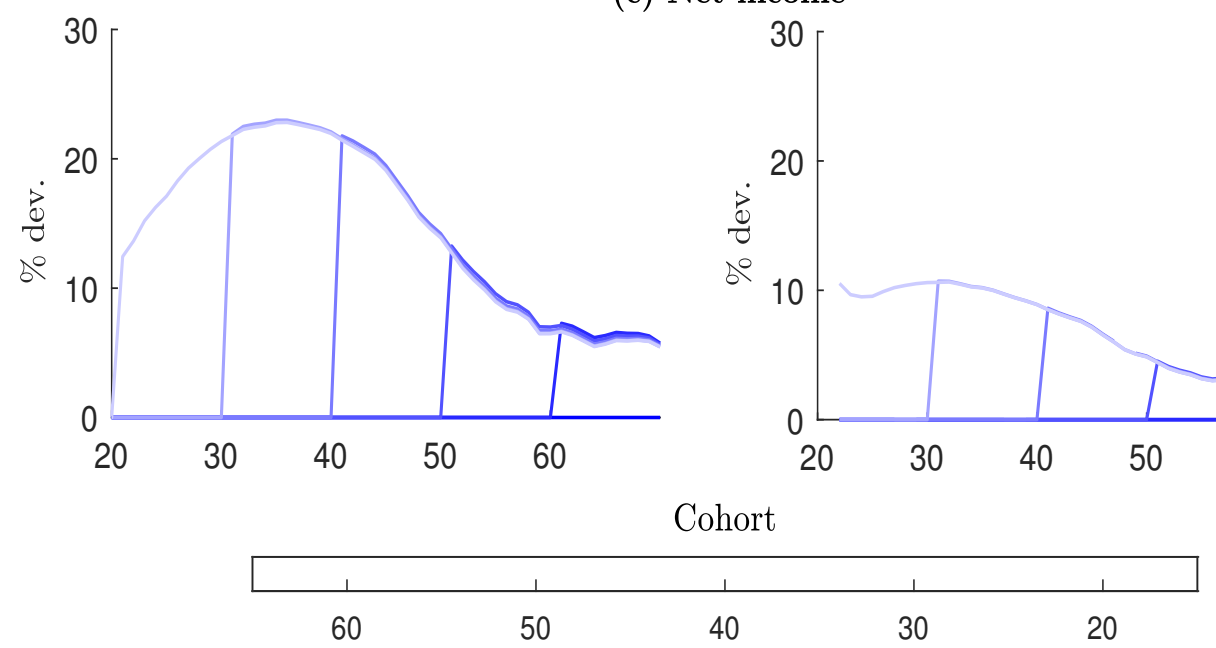

Average life cycle profile of the variables by age at which the change in EITC occurs (doubling in $c_{\max }$ ). Earned income (b): hourly wage rate times hours worked. Net income (c): earned income + EITC + net social transfer. Reading panel (a) unskilled: individuals for which the change in EITC occurs at age 20 will experience a decline in hours worked by around $4.5 \%$ at age 40 compared to the case where the EITC remains unchanged. 
We now turn to the cohort dynamics of employment, search intensity, and tightness. Figure 11 shows that the oldest cohorts do not experience a large drop in employment rate after the implementation of the policy, while the youngest cohorts suffer from a substantial loss along their life cycle, with a peak at 40 . The reform induces a relatively small increase in search intensity but a significant drop in labor market tightness, in particular at the middle of the life-cycle and for the youngest generations. Consequently, the reform has a damaging effect on life-cycle employment and labor market trajectories, especially for people who were young at the time of the reform.

\section{Figure 11: COHORT DYNAMICS (2)}

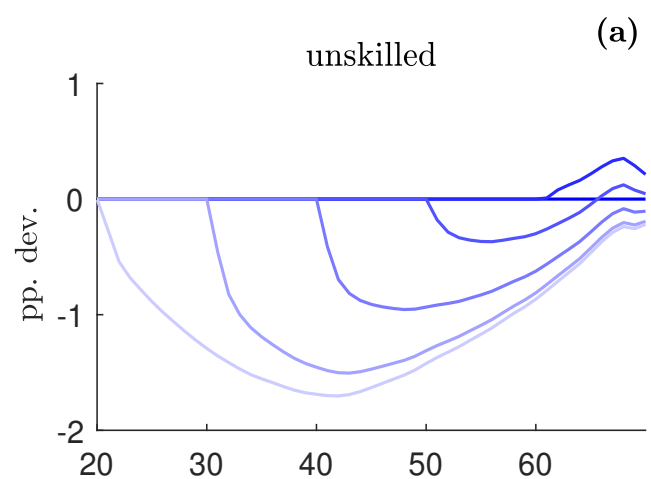

(a) Employment

(c) Search intensity
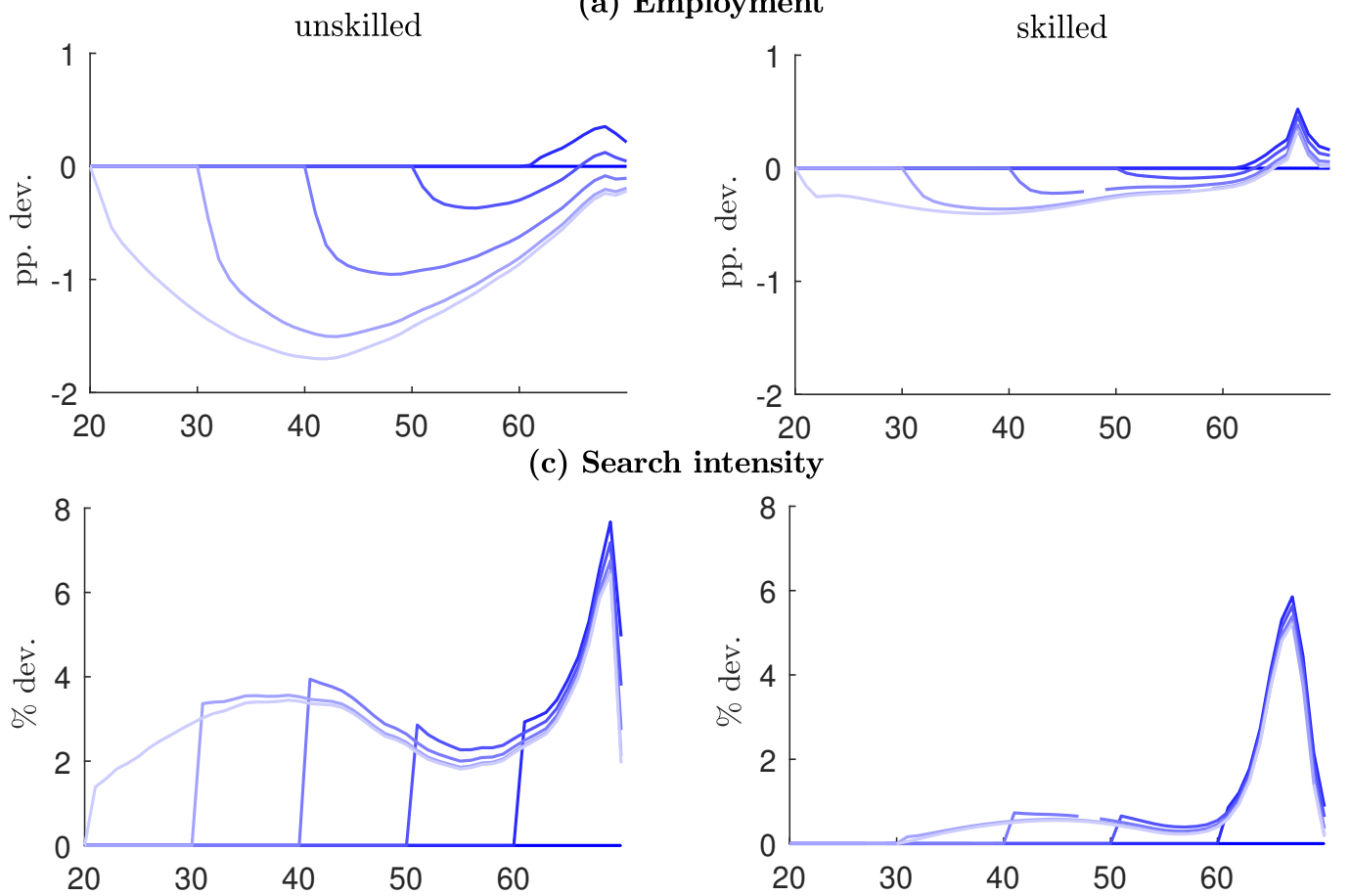

(c) Tightness
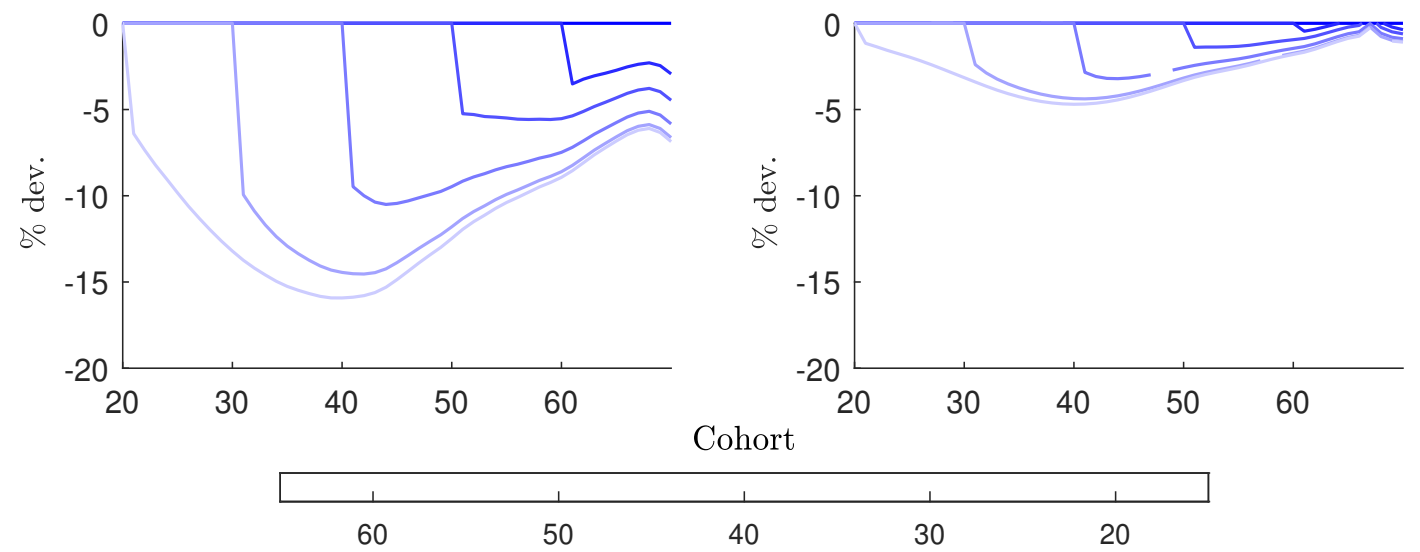

Average life cycle profile of the variables by age at which the change in EITC occurs (doubling in $c_{\max }$ ). Reading panel (a) unskilled: individuals for which the change in EITC occurs at age 40 will experience a decline in employment rate by around 1 percentage points at age 45 compared to the case where the EITC remains unchanged. 


\subsection{Range of EITC}

Our final experiment will assess the non-linear effects of the EITC. We simulate our economy over a plausible range of EITC, i.e., from $c_{\max }^{\prime}=0.5 c_{\max }$ to $c_{\max }^{\prime}=2 c_{\max }$. The lower bound corresponds to a 50\% reduction of the EITC while the upper bound corresponds to a doubling of the EITC.

Panel (e) of Figure 12 shows that, over this range of EITC, the proportion of lowskilled workers in the economy reacts almost linearly to the increase of the maximum amount of EITC a worker can receive. Figure 12 shows the sensitivity of labor market variables to the variation of the EITC. The employment rate of skilled workers remains stable along with this range of EITC, while the employment rate of unskilled workers decreases by one percentage point when doubling the maximum EITC. Together with the composition effect, this induces the total employment rate to fall by more than 2 percentage points. Our simulations predict the same dynamics for hours worked.

What are the consequences in terms of life-cycle earnings? The rise in EITC causes a drop in unskilled earned income by $2 \%$. The effect on total earned income ranges from $+3 \%$ (for a $50 \%$ reduction of EITC) to $-5 \%$ (for a $100 \%$ augmentation of EITC). Note that the total impact on earned income is larger than the effect on unskilled earned income due to a composition effect, i.e., the increase of the proportion of unskilled workers in the economy. Do we reach the same conclusions if we take into account the amount of EITC and transfers received? Panel (d) shows that decreasing the EITC by $50 \%$ would reduce the net income of unskilled workers by $4 \%$, while increasing the EITC by $100 \%$ would increase it from about $5 \%$. At the same time, the net income of high-skilled workers rises slightly with EITC. Taken together, the former effect cannot counterbalance the composition effect, causing the total net income to fall with EITC.

Panel (f) displays the variation of the fiscal surplus given the increase of maximum EITC. We express this surplus as the ratio of government expenditure over the benchmark total payroll (i.e., the payroll without reform). We consider two cases for the public spending in education. In the first, we take the marginal cost of a student for the government to be equal to the average cost. In the second we consider the public expenditure for education fixed, so the marginal cost is equal to zero. We obtain quite similar results in both cases, finding that the increase in EITC causes a drop in the share of agents choosing education, which decreases the spending for education. However, such decrease is offset by (1) the increase in the number of workers entering the EITC program, (2) the direct increase in the generosity of the EITC, and (3) the decrease in government revenues due to the drop in aggregate earnings. At the end of the day, a policy aimed at doubling the maximum EITC would lower the fiscal surplus by 4 percentage points.

Finally, the effects on income inequality are displayed in Figure 13. For the earned income, increasing EITC leads to a fall of the first four deciles, while leaving the others almost unchanged. This result is clearly explained by the composition effect and the decrease in hours worked for workers initially located in the phase-out range and outside the EITC. When considering transfers implied by the welfare and taxation systems, we see that the net income of workers located at the bottom and the top of the distribution does not vary substantially. Phrased differently, the tax credit just allows compensation for the loss in earned income. Consequently, our simulations show that, when considering both the educational system and labor market responses, the EITC does not achieve a significant reduction in income inequalities in the long run. 


\section{Figure 12: LABOR MARKET EFFECTS}

All series are averaged over the life cycle (age 20 to 65). Earned income (c): hourly wage rate times hours worked. Net income (d): earned income + EITC + net social transfer. Fiscal surplus $(f)$ : government revenues minus public expenditures (EITC, transfers and education) divided by total payroll. MC: marginal cost, AC: average cost. Reading panel (a): increasing maximum EITC by 100\% leads to a fall in total employment by more than 2 percentage points. 


\section{Figure 13: EFFECTS ON INCOME DISTRIBUTION}
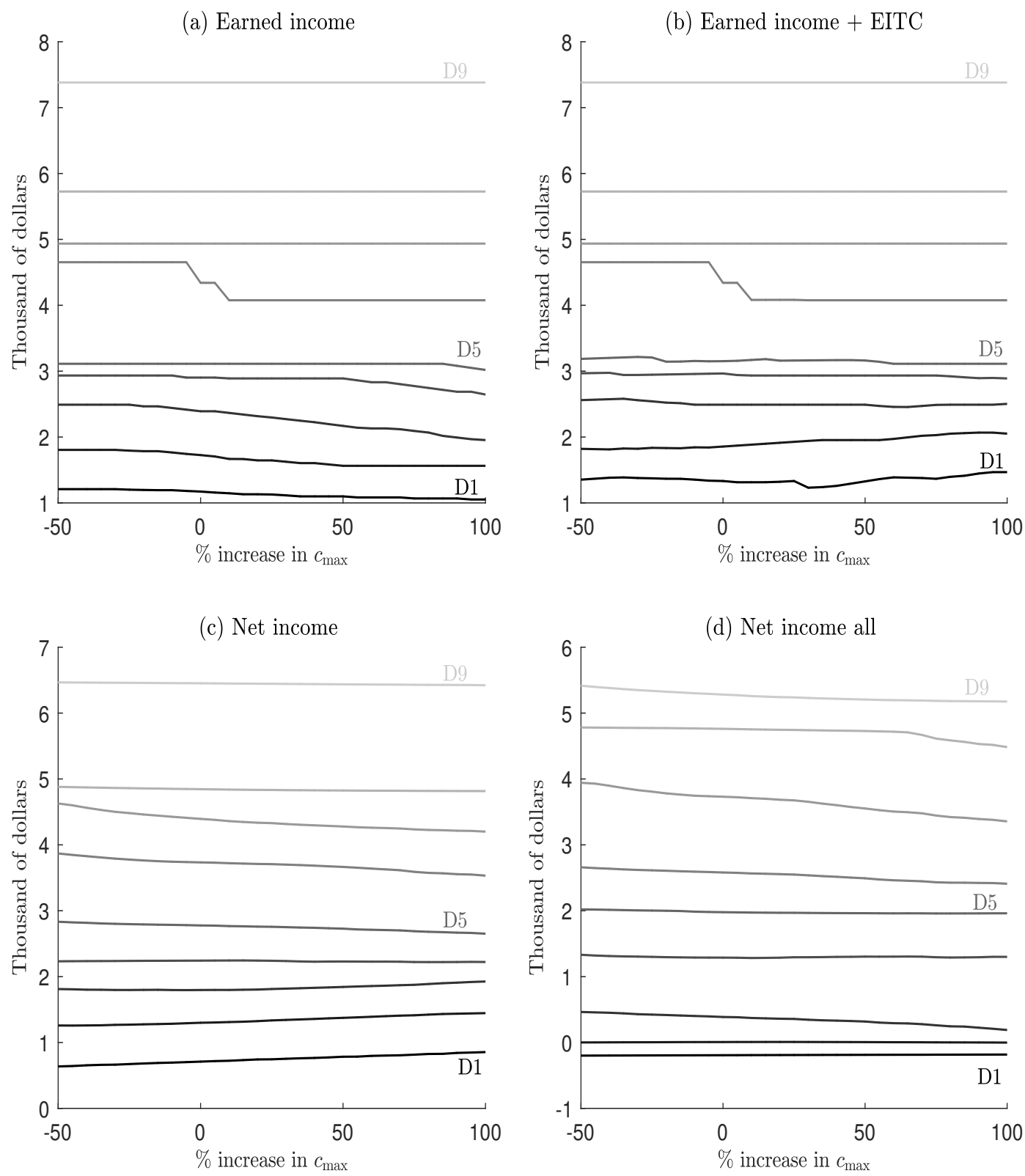

Earned income (a): hourly wage rate times hours worked. Net income (c): Earned income + EITC + net social transfer. Net income all (d): includes net income (c) for employed workers and the transfers to the unemployed workers. It is weighted by the fraction of employed and unemployed workers among the labor force.

\subsection{Discussions and limits}

What conclusions can be drawn? First, the EITC has been implemented to make employment more attractive, to create a financial incentive to participate to the labor market, and to increase low-paid workers' incomes. Although the EITC may induce some positive effects on labor force participation, it causes the aggregate employment rate to fall due to the drop in the low-skilled employment rate and an increase in the proportion of low-skilled workers in the economy. Second, the role of EITC in reducing income inequalities should be put into perspective. When considering the impact of 
EITC on the labor market and education, we show that EITC's redistributive effect is fairly limited in the long term. Third, the financing of EITC is based on the idea that EITC may increase labor force participation, employment, earnings, and so tax collected on labor. We argue that such a scenario is very optimistic, as the composition effect and the fall in hours worked imply that each increase of the EITC causes the fiscal surplus to fall more than proportionally.

Our findings have important implications in terms of public policy. The EITC, as with many fiscal policies, has been the object of a huge debate. Generally, discussions of taxation are based on the trade-off between efficiency and equality. Taking the employment rate and the interquintile range of income as criteria, we show that none of these arguments support an increase in the maximum EITC a worker can receive. Moreover, we show that such a policy may have damaging effects on the government budget.

Another point worth noting is that, although the effects reported in this paper are huge, the EITC could be even more damaging. As shown by Björklund et al. (2006), there is a large correlation between the education level of parents and their children. Various contributions suggest that parental income plays little role in college attendance, but that family background explains a large part of this intergenerational correlation (Cameron and Heckman, 1998, 2001; Carneiro and Heckman, 2002). Children's taste for education may be inherited from their parents. Better educated parents may also offer greater assistance with homework and provide better information about the quality of schools or employment prospects. In our paper, we have considered that the distribution of $\zeta$ (i.e., the aptitude to perform studies) is constant over time. However, it is possible that this distribution shift to the left in the long run as the result of a decline in parental education. In this case, the long-term effects of EITC on education could be even worse. In this sense, the scenarios presented in our paper should be considered as lower bounds of the potential long-term effects of EITC.

\section{Conclusion}

The US, the UK, and some other countries have implemented in-work benefits targeted to low-income (and low-skilled) workers. Our paper provides some evidence that such programs generate disincentives to invest in education. Our empirical strategy based on contiguous PUMA pairs and policy discontinuities at state borders, indicates that each 1-percentage-point increase in state EITC is associated with a statistically significant drop of high school completion by 0.072 percentage point. We find no evidence of cross-border spillovers when comparing border PUMAs to co-contiguous interior PUMAs.

We then develop a life-cycle matching model with directed search in which educational choices, search intensities, hirings, hours worked, and separations are endogenous to investigate the long-term effect of EITC. We show that the EITC achieves its initial goal by increasing labor market participation. However, we highlight two perverse effects. First, a tax credit targeted to low-wage (and low-skilled) workers reduces the relative return to schooling. Individuals react to an increase in EITC by reducing their investment in education, which leads in the long run to a significant increase in the proportion of low-skilled workers in the economy. Second, we show that the vast majority of EITC recipients are initially located in the phase-out range or outside the 
EITC. As a consequence, when the EITC is increased, low-skilled workers react on average by reducing hours worked to benefit from the tax credit. This reduction in hours worked makes low-skilled jobs less profitable for employers, reducing the unskilled employment rate despite a positive effect on participation. This translates into substantial drops in the unskilled employment rate and aggregate earned income. The EITC only slightly compensates for this earned income loss. In turn, it does not play a significant role in reducing income inequalities.

Beyond analyzing the impact of EITC on education and labor market dynamics, our paper draws several important contributions. First, we show that the full effect of a policy can only be appreciated in a life-cycle perspective, when considering not only the labor market response but also the reaction of individuals before entering the labor market (the educational system response). In this sense, we show that studies that ignore the impact of a policy on education also ignore part of the critique leveled by Lucas et al. (1976). Second, our simulations show that the instantaneous employment response of the labor market (the response frequently used to assess the impact of EITC) is derisory compared to the long-run impact of the fall in the education rate. For that reason, studies evaluating the short-term effects of EITC only tell a tiny part of the story. Third, in a life-cycle setting, we challenge the traditional view under which progressive taxation or in-work benefits targeted to low-paid workers may reduce inequality.

Although our paper analyzes the effects of the EITC from a positive point of view, it leaves aside the question of the optimal policy to implement. First, it is natural to wonder what the effects might be of a change in the design of EITC. While interesting, this is a difficult task since it requires exploring the impact of each parameter of the EITC schedule (maximum credit, lower and upper bound of the plateau, upper bound of the phase-out) for each family status. We could go even further by considering EITC schedules that depend on other dimensions (education, age, etc.) or that are not trapeze-shaped. This issue is, however, beyond the scope of this paper. Second, one point remains: If in-work benefits do not improve the situation of low-skilled workers and do not reduce inequalities, what policy should be implemented to achieve these objectives? As shown through our paper, human capital is a key driver of labor market trajectories and life-cycle earnings. This suggests that a natural way to reduce income inequalities is to reduce skill inequalities. In this sense, policies that provide an incentive to accumulate human capital, such as education subsidies or vocational training subsidies, may be good candidates. This issue is on our research agenda. 


\section{References}

Abbott, B., Gallipoli, G., Meghir, C., and Violante, G. L. (2019). Education policy and intergenerational transfers in equilibrium. Journal of Political Economy, 127(6):25692624.

Acemoglu, D. (1996). A microfoundation for social increasing returns in human capital accumulation. The Quarterly Journal of Economics, 111(3):779-804.

Albertini, J. and Terriau, A. (2019). Informality over the life-cycle. Journal of Economic Dynamics and Control, 105:182-202.

Athreya, K., Reilly, D., and Simpson, N. B. (2010). Earned income tax credit recipients: Income, marginal tax rates, wealth, and credit constraints. FRB Richmond Economic Quarterly, 96(3):229-272.

Bagger, J., Fontaine, F., Postel-Vinay, F., and Robin, J.-M. (2014). Tenure, experience, human capital, and wages: A tractable equilibrium search model of wage dynamics. American Economic Review, 104(6):1551-96.

Banfi, S. and Villena-Roldan, B. (2019). Do high-wage jobs attract more applicants? directed search evidence from the online labor market. Journal of Labor Economics, 37(3):715-746.

Becker, G. S. (1962). Investment in human capital: A theoretical analysis. Journal of Political Economy, 70(5, Part 2):9-49.

Björklund, A., Lindahl, M., and Plug, E. (2006). The origins of intergenerational associations: Lessons from swedish adoption data. The Quarterly Journal of Economics, 121(3):999-1028.

Blundell, R. (2006). Earned income tax credit policies: Impact and optimality: The adam smith lecture, 2005. Labour Economics, 13(4):423-443.

Blundell, R., Costa Dias, M., Meghir, C., and Shaw, J. (2016). Female labor supply, human capital, and welfare reform. Econometrica, 84(5):1705-1753.

Burdett, K., Carrillo-Tudela, C., and Coles, M. G. (2011). Human capital accumulation and labor market equilibrium. International Economic Review, 52(3):657-677.

Cameron, S. V. and Heckman, J. J. (1998). Life cycle schooling and dynamic selection bias: Models and evidence for five cohorts of american males. Journal of Political Economy, 106(2):262-333.

Cameron, S. V. and Heckman, J. J. (2001). The dynamics of educational attainment for black, hispanic, and white males. Journal of Political Economy, 109(3):455-499.

Carneiro, P. and Heckman, J. J. (2002). The evidence on credit constraints in postsecondary schooling. The Economic Journal, 112(482):705-734.

Cebula, R. J. and Alexander, G. M. (2006). Determinants of net interstate migration, 2000-2004. Journal of Regional Analysis and Policy, 36(1100-2016-89796). 
Chéron, A., Hairault, J.-O., and Langot, F. (2011). Age-dependent employment protection. The Economic Journal, 121(557):1477-1504.

Chéron, A., Hairault, J.-O., and Langot, F. (2013). Life-cycle equilibrium unemployment. Journal of Labor Economics, 31(4):843-882.

Chéron, A. and Terriau, A. (2018). Life cycle training and equilibrium unemployment. Labour Economics, 50:32-44.

Decreuse, B. and Granier, P. (2013). Unemployment benefits, job protection, and the nature of educational investment. Labour Economics, 23:20-29.

Dickert, S., Houser, S., and Scholz, J. K. (1995). The earned income tax credit and transfer programs: a study of labor market and program participation. Tax Policy and the Economy, 9:1-50.

Donovan, K. and Herrington, C. (2019). Factors affecting college attainment and student ability in the us since 1900. Review of Economic Dynamics, 31:224-244.

Dube, A., Lester, T. W., and Reich, M. (2010). Minimum wage effects across state borders: Estimates using contiguous counties. The Review of Economics and Statistics, 92(4):945-964.

Eissa, N. and Hoynes, H. (2008). Redistribution and tax expenditures: The earned income tax credit. Technical report, National Bureau of Economic Research.

Eissa, N. and Hoynes, H. W. (2004). Taxes and the labor market participation of married couples: the earned income tax credit. Journal of Public Economics, 88(9-10):1931-1958.

Eissa, N. and Liebman, J. B. (1996). Labor supply response to the earned income tax credit. The Quarterly Journal of Economics, 111(2):605-637.

Eissa, N. and Nichols, A. (2005). Tax-transfer policy and labor-market outcomes. American Economic Review, 95(2):88-93.

Hagedorn, M., Manovskii, I., and Mitman, K. (2015). The impact of unemployment benefit extensions on employment: the 2014 employment miracle? Technical report, National Bureau of Economic Research.

Heckman, J. J. and MaCurdy, T. E. (1980). A life cycle model of female labour supply. Review of Economic Studies, 47(1):47-74.

Hoffman, S. D. and Seidman, L. S. (1990). The earned income tax credit: Antipoverty effectiveness and labor market effects. WE Upjohn Institute for Employment Research.

Hoffman, S. D. and Seidman, L. S. (2003). Helping working families: The earned income tax credit. WE Upjohn Institute.

Holmes, T. J. (1998). The effect of state policies on the location of manufacturing: Evidence from state borders. Journal of Political Economy, 106(4):667-705.

Hotz, V. J. (2003). The earned income tax credit. In Means-tested transfer programs in the United States, pages 141-198. University of Chicago press. 
Huang, R. R. (2008). Evaluating the real effect of bank branching deregulation: Comparing contiguous counties across us state borders. Journal of Financial Economics, 87(3):678-705.

Iskhakov, F. and Keane, M. (2020). Effects of taxes and safety net pensions on life-cycle labor supply, savings and human capital: The case of australia. Journal of Econometrics.

Keane, M. and Moffitt, R. (1998). A structural model of multiple welfare program participation and labor supply. International Economic Review, pages 553-589.

Keane, M. P. and Wolpin, K. I. (1997). The career decisions of young men. Journal of Political Economy, 105(3):473-522.

Keane, M. P. and Wolpin, K. I. (2007). Exploring the usefulness of a nonrandom holdout sample for model validation: Welfare effects on female behavior. International Economic Review, 48(4):1351-1378.

Keane, M. P. and Wolpin, K. I. (2010). The role of labor and marriage markets, preference heterogeneity, and the welfare system in the life cycle decisions of black, hispanic, and white women. International Economic Review, 51(3):851-892.

Lalé, E. (2018). Turbulence and the employment experience of older workers. Quantitative Economics, 9(2):735-784.

Ljungqvist, L. and Sargent, T. J. (1998). The European Unemployment Dilemma. Journal of Political Economy, 106(3):514-550.

Ljungqvist, L. and Sargent, T. J. (2008). Two Questions about European Unemployment. Econometrica, 76(1):1-29.

Lucas, R. E. et al. (1976). Econometric policy evaluation: A critique. In CarnegieRochester conference series on public policy, volume 1, pages 19-46.

McFarland, J., Cui, J., Holmes, J., and Wang, X. (2020). Trends in high school dropout and completion rates in the united states: 2019. compendium report. nces 2020-117. National Center for Education Statistics.

Menzio, G., Telyukova, I. A., and Visschers, L. (2016). Directed search over the life cycle. Review of Economic Dynamics, 19:38-62.

Meyer, B. D. and Rosenbaum, D. T. (2001). Welfare, the earned income tax credit, and the labor supply of single mothers. The Quarterly Journal of Economics, 116(3):10631114.

Moffitt, R. A. (2016). Economics of Means-Tested Transfer Programs in the United States, Volume I, volume 1. University of Chicago Press.

Nichols, A. and Rothstein, J. (2015). The earned income tax credit. In Economics of Means-Tested Transfer Programs in the United States, Volume 1, pages 137-218. University of Chicago Press.

Petrongolo, B. and Pissarides, C. A. (2001). Looking into the black box: A survey of the matching function. Journal of Economic Literature, 39(2):390-431. 
Saez, E. (2002). Optimal income transfer programs: intensive versus extensive labor supply responses. The Quarterly Journal of Economics, 117(3):1039-1073.

Scholz, J. K. (1993). Tax policy and the working poor: The earned income tax credit. Focus, 15(3):1-12.

Snyder, T. D., De Brey, C., and Dillow, S. A. (2019). Digest of education statistics 2018, nces 2020-009. National Center for Education Statistics.

Tiebout, C. M. (1956). A pure theory of local expenditures. Journal of Political Economy, 64(5):416-424.

Trampe, P. (2007). The eitc disincentive: The effects on hours worked from the phaseout of the earned income tax credit. Econ Journal Watch, 4(3):308.

Wasmer, E. (2006). General versus specific skills in labor markets with search frictions and firing costs. American Economic Review, 96(3):811-831. 


\section{Appendix}

\section{A Federal EITC parameters}

\begin{tabular}{|c|c|c|c|c|c|c|}
\hline Year & $\begin{array}{l}\text { Number of } \\
\text { children }\end{array}$ & $\begin{array}{c}\text { Phase-in } \\
\text { rate }\end{array}$ & $\begin{array}{l}\text { Phase-in } \\
\text { range }\end{array}$ & $\begin{array}{l}\text { Maximum } \\
\text { credit }\end{array}$ & $\begin{array}{c}\text { Phase-out } \\
\text { rate }\end{array}$ & $\begin{array}{l}\text { Phase-out } \\
\text { range }\end{array}$ \\
\hline \multirow{4}{*}{2018} & No children & 7.65 & $0-6780$ & 519 & 7.65 & $8490-15270$ \\
\hline & One child & 34.00 & $0-10180$ & 3461 & 15.98 & $18660-40320$ \\
\hline & Two children & 40.00 & $0-14290$ & 5716 & 21.06 & $18660-45802$ \\
\hline & Three children & 45.00 & $0-14290$ & 6431 & 21.06 & $18660-49194$ \\
\hline \multirow{4}{*}{2017} & No children & 7.65 & $0-6670$ & 510 & 7.65 & $8340-15010$ \\
\hline & One child & 34.00 & $0-10000$ & 3400 & 15.98 & 18340 - 39617 \\
\hline & Two children & 40.00 & $0-14040$ & 5616 & 21.06 & $18340-45007$ \\
\hline & Three children & 45.00 & $0-14040$ & 6318 & 21.06 & $18340-48340$ \\
\hline \multirow{4}{*}{2016} & No children & 7.65 & $0-6610$ & 506 & 7.65 & $8270-14880$ \\
\hline & One child & 34.00 & $0-9920$ & 3373 & 15.98 & 18190 - 39296 \\
\hline & Two children & 40.00 & $0-13930$ & 5572 & 21.06 & $18190-44648$ \\
\hline & Three children & 45.00 & $0-13930$ & 6269 & 21.06 & $18190-47955$ \\
\hline \multirow{4}{*}{2015} & No children & 7.65 & $0-6580$ & 503 & 7.65 & $8240-14820$ \\
\hline & One child & 34.00 & $0-9880$ & 3359 & 15.98 & 18110 - 39131 \\
\hline & Two children & 40.00 & $0-13870$ & 5548 & 21.06 & $18110-44454$ \\
\hline & Three children & 45.00 & $0-13870$ & 6242 & 21.06 & $18110-47747$ \\
\hline \multirow{4}{*}{2014} & No children & 7.65 & $0-6480$ & 496 & 7.65 & $8110-14590$ \\
\hline & One child & 34.00 & $0-9720$ & 3305 & 15.98 & $17830-38511$ \\
\hline & Two children & 40.00 & $0-13650$ & 5460 & 21.06 & $17830-43756$ \\
\hline & Three children & 45.00 & $0-13650$ & 6143 & 21.06 & 17830 - 46997 \\
\hline \multirow{4}{*}{2013} & No children & 7.65 & $0-6370$ & 487 & 7.65 & 7970 - 14340 \\
\hline & One child & 34.00 & $0-9560$ & 3250 & 15.98 & $17530-37870$ \\
\hline & Two children & 40.00 & $0-13430$ & 5372 & 21.06 & $17530-43038$ \\
\hline & Three children & 45.00 & $0-13430$ & 6044 & 21.06 & $17530-46227$ \\
\hline \multirow{4}{*}{2012} & No children & 7.65 & $0-6210$ & 475 & 7.65 & 7770 - 13980 \\
\hline & One child & 34.00 & $0-9320$ & 3169 & 15.98 & 17090 - 36920 \\
\hline & Two children & 40.00 & $0-13090$ & 5236 & 21.06 & $17090-41952$ \\
\hline & Three children & 45.00 & $0-13090$ & 5891 & 21.06 & $17090-45060$ \\
\hline \multirow{4}{*}{2011} & No children & 7.65 & $0-6070$ & 464 & 7.65 & $7590-13660$ \\
\hline & One child & 34.00 & $0-9100$ & 3094 & 15.98 & $16690-36052$ \\
\hline & Two children & 40.00 & $0-12780$ & 5112 & 21.06 & $16690-40964$ \\
\hline & Three children & 45.00 & $0-12780$ & 5751 & 21.06 & $16690-43998$ \\
\hline
\end{tabular}




\begin{tabular}{|c|c|c|c|c|c|c|}
\hline \multirow{4}{*}{2010} & No children & 7.65 & $0-5980$ & 457 & 7.65 & 7480 - 13460 \\
\hline & One child & 34.00 & $0-8970$ & 3050 & 15.98 & $16450-35535$ \\
\hline & Two children & 40.00 & 0 - 12590 & 5036 & 21.06 & $16450-40363$ \\
\hline & Three children & 45.00 & $0-12590$ & 5666 & 21.06 & $16450-43352$ \\
\hline \multirow{4}{*}{2009} & No children & 7.65 & $0-5970$ & 457 & 7.65 & 7470 - 13440 \\
\hline & One child & 34.00 & $0-8950$ & 3043 & 15.98 & $16420-35463$ \\
\hline & Two children & 40.00 & 0 - 12570 & 5028 & 21.06 & 16420 - 40295 \\
\hline & Three children & 45.00 & 0 - 12570 & 5657 & 21.06 & $16420-43279$ \\
\hline \multirow{3}{*}{2008} & No children & 7.65 & $0-5720$ & 438 & 7.65 & $7160-12880$ \\
\hline & One child & 34.00 & $0-8580$ & 2917 & 15.98 & $15740-33995$ \\
\hline & Two children & 40.00 & $0-12060$ & 4824 & 21.06 & $15740-38646$ \\
\hline \multirow{3}{*}{2007} & No children & 7.65 & $0-5590$ & 428 & 7.65 & $7000-12590$ \\
\hline & One child & 34.00 & $0-8390$ & 2853 & 15.98 & $15390-33241$ \\
\hline & Two children & 40.00 & $0-11790$ & 4716 & 21.06 & $15390-37783$ \\
\hline \multirow{3}{*}{2006} & No children & 7.65 & $0-5380$ & 412 & 7.65 & $6740-12120$ \\
\hline & One child & 34.00 & $0-8080$ & 2747 & 15.98 & $14810-32001$ \\
\hline & Two children & 40.00 & 0 - 11340 & 4536 & 21.06 & $14810-36348$ \\
\hline \multirow{3}{*}{2005} & No children & 7.65 & $0-5220$ & 399 & 7.65 & $6530-11750$ \\
\hline & One child & 34.00 & $0-7830$ & 2662 & 15.98 & $14370-31030$ \\
\hline & Two children & 40.00 & $0-11000$ & 4400 & 21.06 & $14370-35263$ \\
\hline
\end{tabular}

From 2002, the values of the beginning and ending points of the phase-out range were increased for married taxpayers filing jointly. The values for these taxpayers were $\$ 1,000$ higher than the listed values from 2002$2004, \$ 2,000$ higher from 2005-2007; $\$ 3,000$ higher in 2008; $\$ 5,000$ higher in 2009; $\$ 5,010$ higher in 2010; $\$ 5,080$ higher in 2011; $\$ 5,210$ higher in 2012; $\$ 5,340$ higher in 2013; $\$ 5,430$ higher in 2014; $\$ 5,520$ higher in 2015; $\$ 5,550$ higher in 2016; $\$ 5,590$ higher in 2017; $\$ 5,690$ higher for families with children and $\$ 5,680$ for families without children in 2018. 


\section{B State EITC parameters}

\begin{tabular}{|c|c|c|c|c|c|}
\hline State & Tax year & $\begin{array}{l}\text { Rate as \% of } \\
\text { federal EITC }\end{array}$ & State & Tax year & $\begin{array}{l}\text { Rate as \% of } \\
\text { federal EITC }\end{array}$ \\
\hline $\mathrm{CO}$ & $2015-2018$ & 10.00 & : & : & : \\
\hline \multirow[t]{4}{*}{$\mathrm{CT}$} & $2011-2012$ & 30.00 & \multirow{2}{*}{$\dot{\mathrm{MA}}$} & $2005-2015$ & 15.00 \\
\hline & 2013 & 25.00 & & $2016-2018$ & 23.00 \\
\hline & $2014-2016$ & 27.50 & MD & $2005-2018$ & 50.00 \\
\hline & $2017-2018$ & 23.00 & \multirow{3}{*}{ MI } & 2008 & 10.00 \\
\hline \multirow[t]{2}{*}{ DC } & $2005-2007$ & 35.00 & & $2009-2011$ & 20.00 \\
\hline & $2008-2018$ & 40.00 & & $2012-2018$ & 6.00 \\
\hline DE & $2006-2018$ & 20.00 & \multirow[t]{3}{*}{ NC } & 2008 & 3.50 \\
\hline \multirow[t]{4}{*}{ IA } & $2005-2006$ & 6.50 & & $2009-2012$ & 5.00 \\
\hline & $2007-2012$ & 7.00 & & 2013 & 4.50 \\
\hline & 2013 & 14.00 & \multirow[t]{2}{*}{ NE } & 2006 & 8.00 \\
\hline & $2014-2018$ & 15.00 & & $2007-2018$ & 10.00 \\
\hline \multirow[t]{5}{*}{ IL } & $2005-2011$ & 5.00 & \multirow[t]{2}{*}{ NM } & 2007 & 8.00 \\
\hline & 2012 & 7.50 & & $2008-2018$ & 10.00 \\
\hline & $2013-2016$ & 10.00 & NY & $2005-2018$ & 30.00 \\
\hline & 2017 & 14.00 & \multirow[t]{2}{*}{$\mathrm{OH}$} & 2013 & 5.00 \\
\hline & 2018 & 18.00 & & $2014-2018$ & 10.00 \\
\hline \multirow[t]{2}{*}{ IN } & $2005-2008$ & 6.00 & & $2005-2018$ & 5.00 \\
\hline & $2009-2018$ & 9.00 & \multirow[t]{3}{*}{ OR } & $2005-2007$ & 5.00 \\
\hline \multirow[t]{4}{*}{ KS } & $2005-2006$ & 15.00 & & $2008-2013$ & 6.00 \\
\hline & $2007-2009$ & 17.00 & & $2014-2018$ & 8.00 \\
\hline & $2010-2012$ & 18.00 & \multirow[t]{4}{*}{ RI } & $2005-2014$ & 25.00 \\
\hline & $2013-2018$ & 17.00 & & 2015 & 10.00 \\
\hline LA & $2008-2018$ & 3.50 & & 2016 & 12.50 \\
\hline \multirow[t]{4}{*}{ ME } & 2005 & 4.92 & & $2017-2018$ & 15.00 \\
\hline & $2006-2008$ & 5.00 & SC & 2018 & 20.83 \\
\hline & $2009-2010$ & 4.00 & VA & $2006-2018$ & 20.00 \\
\hline & $2011-2018$ & 5.00 & VT & $2005-2017$ & 32.00 \\
\hline$\vdots$ & $\vdots$ & $\vdots$ & & 2018 & 36.00 \\
\hline
\end{tabular}

Source: NBER's Taxsim table corrected by authors 


\section{EITC effect on education - Alternative control group to test for spillover effects}

\begin{tabular}{|c|c|}
\hline VARIABLES & \\
\hline State EITC & $\begin{array}{c}-0.0568^{* *} \\
(0.0272)\end{array}$ \\
\hline \multicolumn{2}{|l|}{ Controls } \\
\hline PUMA-pair $\times$ period dummies & YES \\
\hline Demographic characteristics & YES \\
\hline Parental environment & YES \\
\hline Labor market conditions & YES \\
\hline State policy variables & YES \\
\hline Number of periods & 14 \\
\hline Number of PUMA-pairs & 401 \\
\hline R-squared & 0.8139 \\
\hline
\end{tabular}




\section{Data description}

In our study, we take advantage of four datasets provided by IPUMS:

i) American Community Survey (ACS)

ii) Current Population Survey - Basic Monthly Survey (CPS - BSM)

iii) Current Population Survey - Earner Study (CPS - ES)

iv) Current Population Survey - Annual Social and Economic Supplement (CPS - ASEC)

The following appendix provides a full description of the datasets used in our study.

\section{D.1 American Community Survey (ACS) \\ D.1.1 Description}

The ACS is a 1-in-100 national random sample of the population, specifically designed to analyze long-term trends in education, employment, income, and family patterns. ACS 1-year estimates are published each year and are available for a broad range of geographic areas. The smallest identifiable geographic unit is the Public Use Microdata Area (PUMA). PUMAs cover the entirety of the United States. Each state is divided into a series of PUMAs, containing at least 100000 persons. PUMAs are built on county and neighborhood boundaries and do not cross state lines. In our study, we use the ACS 1-year for the period 2005-2018, extracted from IPUMS at https://usa.ipums.org/usa/, to estimate the effect of state EITC on education using policy discontinuities at state borders.

\section{D.1.2 Sample}

Our sample is restricted to respondents who are part of the American Community Survey (ACS) between 2005 and 2018. Our empirical strategy requires to limit the sample to states in which EITC is expressed as a percentage of the federal EITC (regardless of the number of children), and that share a border with at least one other state. For these reasons,

i) we drop Alaska and Hawaii that do not share a border with another state.

ii) we exclude California that has implemented a state EITC (from 2015) that is not expressed as a percentage of the federal EITC.

iii) we exclude New Jersey and Wisconsin that are the only two states where the credit rate depends on the number of children.

\section{D.1.3 Variables}

The variable State EITC is determined at the state level. For other variables, we use the PUMA as the unit of analysis.

Year: This variable is taken from IPUMS variable YEAR.

State EITC: This variable corresponds to the state EITC (as a percentage of the federal EITC), reported in Appendix B. 
PUMAs: PUMA definitions are altered after each decennial census, so PUMA codes are not consistently comparable across time. To support spatio-temporal analysis, we use IPUMS variable CPUMA0010 that identifies consistent PUMAs over the period 2005-2018. We then use boundary files provided by IPUMS (see the next subsection for more details) to match each PUMA to the state to which it belongs.

Age: This variable is taken from IPUMS variable AGE.

High school completion rate: Among 18- to 24-year-olds (IPUMS variable AGE = 18-24) who are not enrolled in high school or a lower education level (IPUMS variable GRADEATT $\neq$ 1-5), the percentage who hold a high school diploma or alternative credential (IPUMS variable EDUC = 6-11).

Male: This variable equals one if the respondent is male (IPUMS variable SEX $=1$ ) and zero otherwise.

Race: This variable is taken from IPUMS variable RACE.

\section{D.1.4 Supplementary material}

Boundary files for PUMAs: We use IPUMS GIS boundary files available at https://usa. ipums.org/usa/volii/boundaries.shtml to define PUMA boundaries and to compute the contiguity matrix of PUMAs.

Boundary files for states: We use IPUMS GIS boundary files available at https: //www . nhgis . org/ to define state boundaries and to compute the contiguity matrix of states.

\section{D.2 Current Population Survey - Basic Monthly Survey (CPS - BSM)}

\section{D.2.1 Description}

The CPS - BSM is the primary source of labor force statistics for the population of the United States. It provides a comprehensive body of monthly data on employment and labor force characteristics. In our study, we use the CPS - BSM, extracted from IPUMS at https://cps . ipums.org/cps/, to compute the life-cycle transition matrices across employment status and family status. We also use the CPS - BSM to determine the employment rate by age and education.

\section{D.2.2 Sample}

Our sample is restricted to respondents who are part of the Basic Monthly Survey (BSM) between $2005 \mathrm{~m} 1$ and $2018 \mathrm{~m} 12$. We use IPUMS variable CPSIDP to identify individuals across CPS samples. We use the all-age sample to determine the number of EITC eligible children, and then compute the monthly transition matrices from age 20 to 69. 


\section{D.2.3 Variables}

Time: This variable is constructed by combining IPUMS variables YEAR and MONTH.

Age: This variable is taken from IPUMS variable AGE and is top-coded at 80.

High school completed: This variable equals one if the respondent has completed high school (IPUMS variable EDUC = 70-125) and zero otherwise.

Employed: This variable equals one if the respondent is employed (IPUMS variable EMPSTAT $=1-12$ ) and zero otherwise.

Married: This variable equals one if the respondent is married (IPUMS variable MARST $=1-2$ ) and zero otherwise.

Number of EITC eligible children: This variable identifies the number of EITC eligible children a respondent has. An EITC eligible child is a household member (child, stepchild, sibling, grandchild, or foster child) (IPUMS variable RELATE $=301,303,701$, 901, or 1242) who is either under 19 (IPUMS variable AGE < 19) or younger than 24 and a full-time student (IPUMS variable AGE $<24$ \& IPUMS variable EMPSTAT $=33$ ).

\section{D.2.4 Supplementary material}

Life-cycle transition matrices across employment status: We use the variable Employed to define the employment status ( $\mathrm{N}=$ Nonemployed, E=Employed). We follow Menzio et al. (2016) and Albertini and Terriau (2019) to determine the age profile of transitions across employment status:

i) we consider that an individual experiences a NE transition if she is nonemployed in a given month and employed the next month.

ii) we consider that an individual experiences an EN transition if she is employed in a given month and nonemployed the next month.

iii) we consider that an individual experiences an EE pattern if she is employed in a given month and still employed the next month.

iv) we consider that an individual experiences a NN pattern if she is nonemployed in a given month and still nonemployed the next month.

The life-cycle transition matrices across employment status are determined using monthly transitions for a given age. Transitions matrices are determined separately for high-educated and low-educated individuals.

Life-cycle transition matrices across family status: We use the variable Number of EITC eligible children to define the family status (Child0=No EITC eligible children, Child1=One EITC eligible children, Child2=Two EITC eligible children, Child3=Three or more EITC eligible children). We then adopt a similar approach to determine the age profile of transitions across family status. The life-cycle transition matrices across family status are determined using monthly transitions for a given age. Transitions matrices are determined separately for high-educated and low-educated individuals. 


\section{D.3 Current Population Survey - Earner Study (CPS - ES) \\ D.3.1 Description}

Every household that enters the CPS is interviewed each month for 4 months, then ignored for 8 months, and then interviewed again for 4 more months. Households that are interviewed for the fourth month or eighth month (that is, the households that are about to rotate out of interviews for eight months or indefinitely) are asked additional labor questions. The outgoing rotation group questions, also known as the CPS - Earner Study, provide rich and reliable information on current earnings and hours worked. In our study, we use the CPS - ES, extracted from IPUMS at https://cps.ipums.org/cps/, to compute the life-cycle profiles of wages and hours worked.

\section{D.3.2 Sample}

Our sample is restricted to respondents who are part of the Earner Study (ES) between 2005 and 2018. We use the all-age sample to determine the number of EITC eligible children, and then compute the life-cycle profiles from age 20 to 69.

\section{D.3.3 Variables}

Age: This variable is taken from IPUMS variable AGE and is top-coded at 80.

High school completed: This variable equals one if the respondent has completed high school (IPUMS variable EDUC = 70-125) and zero otherwise.

Employed: This variable equals one if the respondent is employed (IPUMS variable EMPSTAT $=1-12$ ) and zero otherwise.

Married: This variable equals one if the respondent is married (IPUMS variable MARST $=1-2$ ) and zero otherwise.

Number of EITC eligible children: This variable identifies the number of EITC eligible children a respondent has. An EITC eligible child is a household member (child, stepchild, sibling, grandchild, or foster child) (IPUMS variable RELATE $=301,303,701$, 901, or 1242) who is either under 19 (IPUMS variable AGE < 19) or younger than 24 and a full-time student (IPUMS variable AGE < 24 \& IPUMS variable EMPSTAT $=33$ ).

Male: This variable equals one if the respondent is male (IPUMS variable SEX = 1) and zero otherwise.

Race: This variable is taken from IPUMS variable RACE.

Hours worked per month: This variable corresponds to the number of hours usually worked per week at current job (IPUMS variable UHRSWORK1) multiplied by 52/12.

Monthly wage: This variable corresponds to the income usually earned per week at current job (IPUMS variable EARNWEEK) multiplied by 52/12. 
Hourly wage: This variable corresponds to the Monthly wage divided by the number of Hours worked per month.

\section{D.3.4 Supplementary material}

All dollar amounts are adjusted for inflation using IPUMS variable CPI99. All values are expressed in 2018 dollars.

\section{D.4 Current Population Survey - Annual Social and Economic Supple- ment (CPS - ASEC)}

\section{D.4.1 Description}

The CPS - ASEC is a supplemental survey that provides rich data on income and tax liability. In our study, we use the CPS - ASEC, extracted from IPUMS at https://cps.ipums.org/ $\mathrm{cps} /$, to compute net social transfer over the life cycle.

\section{D.4.2 Sample}

Our sample is restricted to respondents who are part of the Annual Social and Economic Supplement (ASEC) between 2005 and 2018. We use the all-age sample to determine the number of EITC eligible children, and then compute the net social transfer from age 20 to 69.

\section{D.4.3 Variables}

Age: This variable is taken from IPUMS variable AGE and is top-coded at 80.

High school completed: This variable equals one if the respondent has completed high school (IPUMS variable EDUC = 70-125) and zero otherwise.

Employed: This variable equals one if the respondent is employed (IPUMS variable EMPSTAT $=1-12$ ) and zero otherwise.

Married: This variable equals one if the respondent is married (IPUMS variable MARST $=1-2$ ) and zero otherwise.

Number of EITC eligible children: This variable identifies the number of EITC eligible children a respondent has. An EITC eligible child is a household member (child, stepchild, sibling, grandchild, or foster child) (IPUMS variable RELATE = 301, 303, 701, 901, or 1242) who is either under 19 (IPUMS variable AGE < 19) or younger than 24 and a full-time student (IPUMS variable AGE < 24 \& IPUMS variable EMPSTAT = 33).

Welfare: This variable is taken from IPUMS variable INCWELFR and corresponds to the amount received by a respondent from various public assistance programs commonly referred to as "welfare".

Unemployment Benefits: This variable is taken from IPUMS variable INCUNEMP and corresponds to the amount received by a respondent from unemployment benefits. 
Worker's Compensation: This variable is taken from IPUMS variable INCWKCOM and corresponds to the amount received by a respondent from worker's compensation.

Educational Assistance: This variable is taken from IPUMS variable INCEDUC and corresponds to the amount received by a respondent from educational assistance.

Income Tax Liability: This variable identifies the net transfer from the income tax system, excluding the EITC. It corresponds to the sum of Federal and State income tax liability, after tax credits are deducted (IPUMS variables FEDTAXAC and STATAXAC). It includes the child tax credit but excludes the EITC (IPUMS variable EITCRED), whose structure is directly reproduced in our programs.

Net social transfer: This variable identifies the net social transfer, depending on age, education, labor force status and family status. It corresponds to: Welfare + Unemployment Benefits + Worker's Compensation + Educational Assistance - Income Tax Liability.

\section{D.4.4 Supplementary material}

All dollar amounts are adjusted for inflation using IPUMS variable CPI99. All values are expressed in 2018 dollars. 


\section{E Public and private costs of education}

In order to calibrate the college costs, we follow Donovan and Herrington (2019) and we use the tables of the Digest of Education Statistics ${ }^{12}$, taking 2018 as a reference year. We denote $C_{S}$ the annual private college costs. We use Table 301.10 to calculate the number of students enrolled in every degree-granting institution (public, non-profit and for-profit institutions). Table 330.10 gives us the average tuition and fees per undergraduate student in all institutions combined. We calculate the public cost of education, $C_{p}$, from the revenue of public and private institutions. We use tables 333.10, 333.40 and 333.55 for the public aid received by public, non-profit and for-profit institutions respectively. We sum the federal and local funding for grants and contracts for every institution. The amount divided by the number of students gives us the average cost per undergraduate student enrolled in a degree granting institution.

\footnotetext{
${ }^{12}$ See Snyder et al. (2019)
} 


\section{F Life-cycle wage profiles}

To construct the life-cycle wage profiles, we estimate the following model:

$$
\omega_{i t}=\alpha_{1}+\sum_{j=0,1} \beta_{a}^{j} A g e_{i t} \mathbb{1}_{\left\{h_{i t}=j\right\}}+\beta_{c} C_{i t}+\beta_{t} D_{t}+\gamma_{i}+u_{i t}
$$

where $\omega$ is the wage, $C$ is a set of sociodemographic characteristics, $D$ is a set of year dummy variables, and $\gamma_{i}$ an individual specific-effect. We consider that $h_{i t}=1$ if a worker is highskilled (i.e. she completed high school), and $h_{i t}=0$ otherwise. We then use the age and education effects to construct the mean life-cycle profiles (see Figure 6), which represent the empirical counterpart of the profiles simulated by our model. 


\section{G Net social transfer}

Figure 14: NET SOCIAL TRANSFER $b$
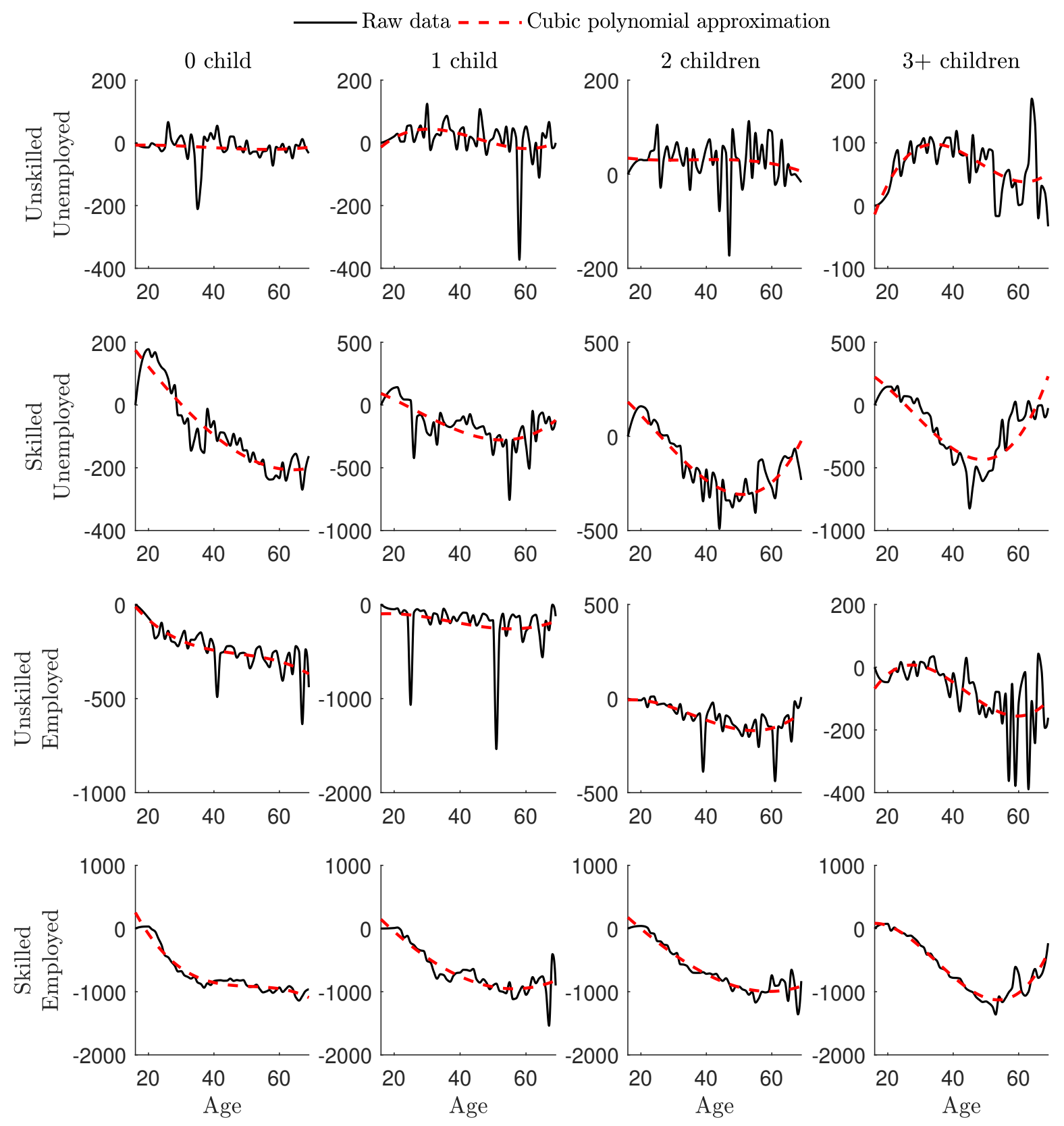

Net social transfer (welfare less taxes), depending on age, education, labor force status, and family status (see Appendix D.4 for more details). 


\section{H Transition probabilities and family status proportions}

Figure 15: TRANSITION PROBABILITIES
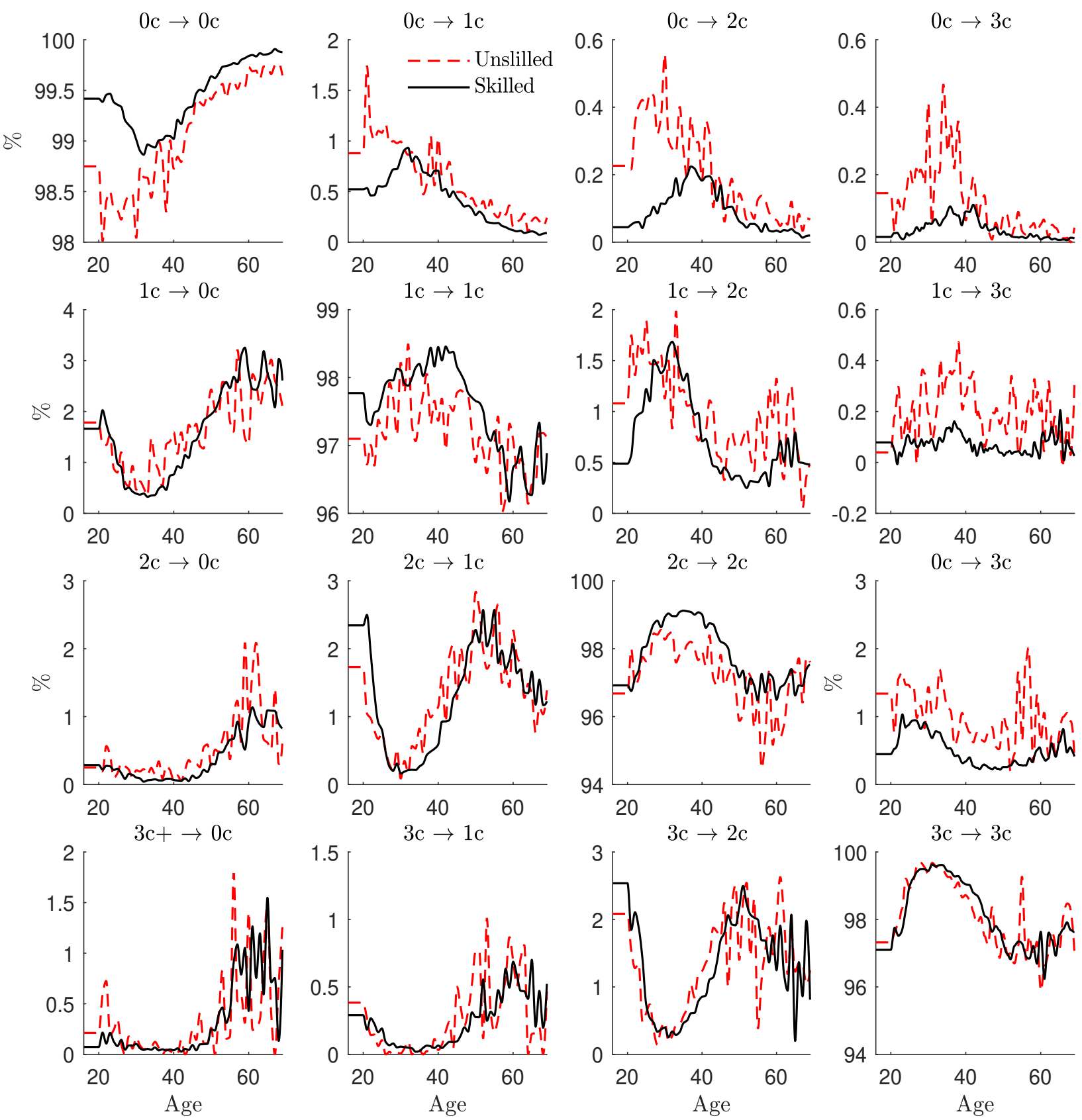
Figure 16: FAMILY STATUS PROPORTIONS
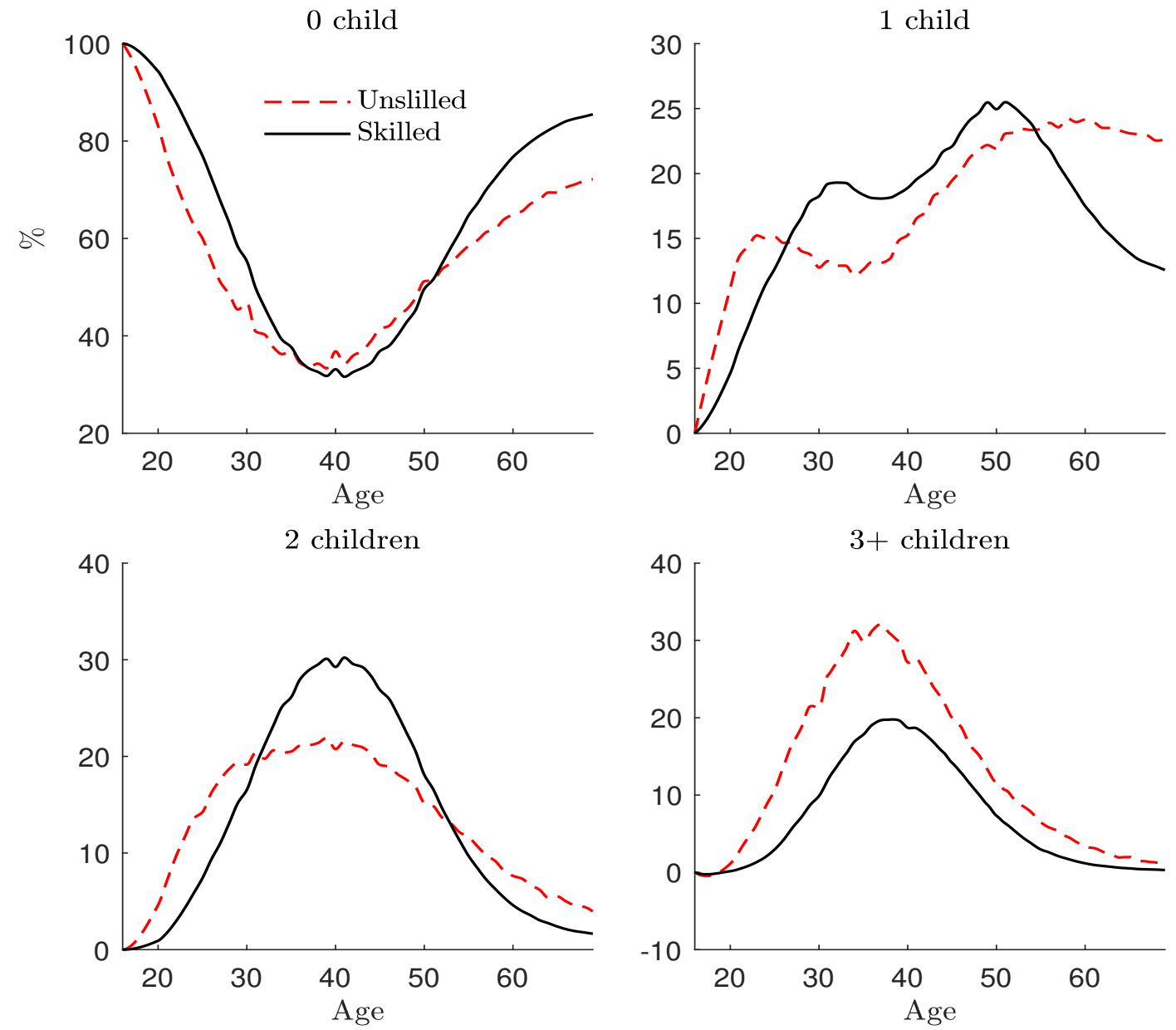


\title{
The impact of EITC on education, labor market trajectories, and inequalities Online appendix
}

\author{
Julien Albertini*
}

\author{
Arthur Poirier ${ }^{\dagger}$
}

Anthony Terriau ${ }^{\ddagger}$

December 15, 2020

\section{Solution algorithm}

The numerical solution technique consists in finding a set of (a) value functions $J, W$ and $U,(b)$ probabilities $p$ and $q$, (c) optimal decision rules $s$ and $\ell,(d)$ educational choices $e^{*}$, and (e) stationary distributions $u$ and $n$. (a)-(b) are solved backward using terminal conditions. (d) is solved given value functions, and (e) is solved forward using initial conditions and iterating forward on the law of motion for unemployment and employment. All these steps are repeated until convergence. Note that the value of the wage rate $w$, the benefits $b$ and the tax schedule parameters $w_{m}, \bar{w}, \underline{w}, c_{\max }$ are calibrated using the data. To set their level, we proceed as follow:

1 In the data, we compute the median earned income $G W_{\text {median }}^{d}$

2 We convert the observed values $b, w_{m}, \bar{w}, \underline{w}, c_{\max }$ in percentage deviation from $G W_{\text {median }}^{d}$.

$$
\operatorname{dev}_{j}=j / G W_{\text {median' }}^{d} j=b, w_{m}, \bar{w}, \underline{w}, c_{\max }
$$

3 In the model, for an initial guess of the median earned income $G W_{\text {median' }}^{m}$ we calibrate $b, w_{m}, \bar{w}, \underline{w}, c_{\max }$ using the deviations $\operatorname{dev}_{j}$ obtained in the previous step.

4 We denote by $G W_{\text {median }}^{m, i}$ the median earned income at iteration $i$. After computing value functions, optimal decision rules and the stationary distributions, we calculate the median earned income from the model at iteration $i+1, G W_{\text {median }}^{m, i+1}$. We iterate until its value between iteration $i$ and $i+1$ is lower than a threshold $\varepsilon$.

*GATE, University of Lyon 2

${ }^{\dagger}$ GAINS, University of Le Mans

$\ddagger$ GAINS, University of Le Mans 


\subsection{State-space}

The state-space is given by a set of points for age $a=1, \ldots, A$, human capital $h=1, \ldots, H$, family status $f=1, \ldots, F$, idiosyncratic productivity $x=1, \ldots, X$ and education level $e=1, \ldots, E$. The age evolves deterministically. The human capital moves stochastically. With probability $\psi_{n}$ the human capital of an employed worker switches from $h$ to $h+$ $1<H$. Similarly, with probability $\psi_{u}$ the human capital of an unemployed worker switches from $h$ to $h-1>1$. $f$ and $x$ follow two independent Markov processes. For the family status $f$, the age- and education-dependent transition matrix is given by:

$$
G_{a, e}\left(f^{\prime} \mid f\right)=\left[\begin{array}{ccc}
G_{1,1} & \cdots & G_{1, F} \\
\vdots & \ddots & \vdots \\
G_{F, 1} & \cdots & G_{F, F}
\end{array}\right]
$$

The matrix is estimated using CPS data.

For the idiosyncratic productivity shock, we consider a first-order autoregressive process:

$$
x^{\prime}=\rho_{x} x+\sigma_{x} \varepsilon_{x}^{\prime}
$$

with $\varepsilon_{x}^{\prime} \sim \mathcal{N}(0,1)$. The process is discretized using the method of Rouwenhorst. This discretization technique gives the points of the grid $\left\{x_{1}, \ldots, x_{H}\right\}$ and the transition matrix:

$$
Z\left(x^{\prime} \mid x\right)=\left[\begin{array}{ccc}
Z_{1,1} & \cdots & Z_{1, X} \\
\vdots & \ddots & \vdots \\
Z_{X, 1} & \cdots & Z_{X, X}
\end{array}\right]
$$

The probability density function for individual productivity of the new matches is uniform with probabilities:

$$
Z_{0}=\frac{1}{X}
$$

Table 1: SUMMARY OF STATE-SPACE PARAMETERS

\begin{tabular}{lcc}
\hline Parameter & Symbol & Value \\
\hline Number of age groups (monthly) & $A$ & 637 \\
Expected entry age - unskilled & $a \_0$ & 16 \\
Expected entry age - skilled & $a \_0+d_{-} 2$ & 19 \\
Final age & $a_{A}$ & 69 \\
\hline Number of human capital levels & $\mathrm{H}$ & 5 \\
Human capital range & {$\left[h_{1}, h_{5}\right]$} & {$[1.0,5.0]$} \\
\hline Number of family status & $F$ & 4 \\
\hline Number of idio. prod. levels & $X$ & 3 \\
Persistence of idio. prod. & $\rho_{x}$ & 0.8429 \\
Standard deviation of idio. prod. & $\sigma_{x}$ & 0.1897 \\
\hline Number of education levels & $E$ & 2 \\
\hline
\end{tabular}




\subsection{Value function iteration}

Let $Y_{a}$ be a control variable at age $a$. We consider the following terminal condition (age $a=A)$ :

$$
Y_{A}=0, \quad Y=J, W, U, p, q, s, \ell
$$

The algorithm consists in iterating backward the value functions, starting from the terminal condition and using the Bellman equation and the job creation conditions in a recursive manner. It is worth noting that the hourly wage rate $w$, the level of hours worked $\ell$ and the productivity of the job $y$ can be computed outside of this backward loop.

Step 1. For each human capital level $h$, age $a$, idiosyncratic productivity shock $x$, family status $f$ and education level $e$, compute:

$$
\begin{aligned}
w(h, a, f, x, e)= & A_{e} x h^{\bar{\alpha}_{e}} \\
0= & w(h, a, f, x, e)-w(h, a, f, x, e) \tau^{\prime}(w(h, a, f, x, e) \ell(h, a, f, x, e)) \\
& -\eta(a, e) \operatorname{ell}(h, a, f, x, e) \phi \\
y(h, a, f, x, e)= & A_{e} x h \ell(h, a, f, x, e)
\end{aligned}
$$

Step 2. Consider initial conditions and set age $a=A$.

Step 3. Set age $a=a-1$.

Step 4. For each human capital level $h$, idiosyncratic productivity shock $x$, family status $f$ and education level $e$, solve the integrals:

$$
\begin{aligned}
\mathcal{I}_{\Omega}(h, a, f, x, e) & =\int_{f^{\prime}} \int_{x^{\prime}} \Omega\left(h, a^{\prime}, f^{\prime}, x^{\prime}, e\right) d Z\left(x^{\prime} \mid x\right) d G_{a, e}\left(f^{\prime} \mid f\right) \\
\mathcal{I}_{\Omega_{0}}(h, a, f, e) & =\int_{f^{\prime}} \int_{x^{\prime}} \Omega\left(h, a^{\prime}, f^{\prime}, x^{\prime}, e\right) d Z_{0}\left(x^{\prime}\right) d G_{a, e}\left(f^{\prime} \mid f\right) \\
\mathcal{I}_{\Lambda}(h, a, f, x, e) & =\int_{f^{\prime}} \int_{x^{\prime}} \Lambda\left(h, a^{\prime}, f^{\prime}, x^{\prime}, e\right) d Z\left(x^{\prime} \mid x\right) d G_{a, e}\left(f^{\prime} \mid f\right) \\
\mathcal{I}_{V}(h, a, e) & =\int_{f^{\prime}} \int_{x^{\prime}} \pi\left(h, a, f^{\prime}, e\right) \Lambda\left(h, a^{\prime}, f^{\prime}, x^{\prime}, e\right) d Z_{0}\left(x^{\prime}\right) d f^{\prime} \\
\mathcal{I}_{U}(h, a, f, e) & =\int_{f^{\prime}} U\left(h, a^{\prime}, f^{\prime}, e\right) d G_{a, e}\left(f^{\prime} \mid f\right)
\end{aligned}
$$

Step 5. For each human capital level $h$ and education level $e$, solve for the job finding probabilities using the job creation condition:

$$
\begin{aligned}
q(h, a, e) & =c_{e} \mathcal{I}_{V}(h, a, e)^{-1} \\
\theta(h, a, e) & =\left(\frac{q(h, a, e)}{\chi}\right)^{-1 / v} \\
p(h, a, e) & =\theta(h, a, e) q(h, a, e)
\end{aligned}
$$


Step 6. For each human capital level $h$, family status $f$ and education level $e$, solve the optimal search intensity and the unemployed value function:

$$
\begin{aligned}
s(h, a, f, e)= & k^{-1}\left[p(h, a, e) \beta \sum_{h^{\prime}} \mu_{u}\left(h, h^{\prime}\right)\left(\mathcal{I}_{\Omega_{0}}\left(h^{\prime}, a, f, e\right)-\int_{x^{\prime}} \mathcal{I}_{U}\left(h^{\prime}, a, f, e\right) d Z_{0}\left(x^{\prime}\right)\right)\right] \\
U(h, a, f, e)= & b(a, f, e, u)-k(s(h, a, f, e)) \\
& +\beta \sum_{h^{\prime}} \mu_{u}\left(h, h^{\prime}\right)\left[\begin{array}{l}
p(h, a, e) s\left(h^{\prime}, a, f, e\right) \mathcal{I}_{\Omega_{0}}\left(h^{\prime}, a, f, e\right) \\
+\left(1-p(h, a, e) s\left(h^{\prime}, a, f, e\right)\right) \int_{x^{\prime}} \mathcal{I}_{U}\left(h^{\prime}, a^{\prime}, f^{\prime}, e\right) d Z_{0}\left(x^{\prime}\right)
\end{array}\right]
\end{aligned}
$$

Step 7. For each human capital level $h$, idiosyncratic productivity shock $x$, family status $f$ and education level $e$, solve the employed value function and the firm value function:

$$
\begin{aligned}
W(h, a, f, x, e)= & w(h, a, f, x, e) \ell(h, a, f, x, e)-\tau(w(h, a, f, x, e) \ell(h, a, f, x, e)) \\
& +b(a, f, e, n)-\eta(a, e) \frac{\ell(h, a, f, x, e)^{1+\phi}}{1+\phi} \\
& +\beta \sum_{h^{\prime}} \mu_{n}\left(h, h^{\prime}\right) \int_{f^{\prime}} \int_{x^{\prime}}\left[\begin{array}{r}
\delta_{e} \\
\mathcal{I}_{U}\left(h^{\prime}, a, f, e\right) \\
+\left(1-\delta_{e}\right) \mathcal{I}_{\Omega}\left(h^{\prime}, a, f, x, e\right)
\end{array}\right] \\
J(h, a, f, x, e)= & \max \left\{\begin{array}{l}
y(h, a, f, x, e)-w(h, a, f, x, e) \ell(h, a, f, x, e) \\
0 \beta \sum_{h^{\prime}} \mu_{n}\left(h, h^{\prime}\right)\left(1-\delta_{e}\right) \mathcal{I}_{\Lambda}\left(h^{\prime}, a, f, x, e\right)
\end{array}\right\}
\end{aligned}
$$

Step 8. Return to Step 2 until $a=1$

\subsection{Stationary distribution}

We consider the following initial condition:

$$
u\left(h_{1}, a_{0}+d_{e}, f, e\right)=1
$$

Before age $a_{0}+d_{e}$ there is no labor force. Note also that all individuals entering the labor market have the lowest human capital. Denote by the $\mathbb{1}\{h, a, f, x, e\}$ The effective optimal separation decisions.

Step 9. Set age $a=a+1$.

Step 10. For each human capital level $h$, idiosyncratic productivity shock $x$, family status $f$, and education level $e$, compute the following integrals:

$$
\begin{aligned}
\mathcal{I}_{n}(h, a, f, x, e) & =\int_{f^{\prime}} \int_{x^{\prime}} n\left(h, a-1, f^{\prime}, x^{\prime}, e\right) d Z\left(x \mid x^{\prime}\right) d G_{a-1, e}\left(f \mid f^{\prime}\right) \\
\mathcal{I}_{u}(h, a, f, e) & =\int_{f^{\prime}} \int_{x^{\prime}} u\left(h, a-1, f^{\prime}, e\right) s\left(h, a-1, f^{\prime}, e\right) d Z_{0}\left(x^{\prime}\right) d G_{a-1, e}\left(f \mid f^{\prime}\right)
\end{aligned}
$$

Step 11. For each human capital level $h$, idiosyncratic productivity shock $x$, family status $f$, and education level $e$, compute employment, 


$$
\begin{aligned}
n(h, a, f, x, e)= & \mathbb{1}\{h, a, f, x, e\}\left[\psi_{n}\left(1-\delta_{e}\right) \mathcal{I}_{n}(h-1, a, f, x, e)\right. \\
& +\left(1-\psi_{n}\right)\left(1-\delta_{e}\right) \mathcal{I}_{n}(h, a, f, x, e) \\
& +\psi_{u} p(h, a-1, e) \mathcal{I}_{u}(h+1, a, f, e) p(h, a-1, e) \\
& \left.+\left(1-\psi_{u}\right) p(h, a-1, e) \mathcal{I}_{u}(h, a, f, e)\right]
\end{aligned}
$$

Step 12. For each human capital level $h$, idiosyncratic productivity shock $x$, family status $f$ and education level $e$, compute unemployment:

$$
\begin{aligned}
u(h, a, f, e)= & \left(1-\psi_{n}\right) \int_{x}\left(\delta_{e}+(1-\mathbb{1}\{h, a, f, x, e\})\right) \mathcal{I}_{n}(h, a, f, x, e) d x \\
& +\psi_{n} \int_{x}\left(\delta_{e}+(1-\mathbb{1}\{h, a, f, x, e\})\right) \mathcal{I}_{n}(h-1, a, f, x, e) d x \\
& +\left(1-\psi_{u}\right) \int_{f^{\prime}} u\left(h, a-1, f^{\prime}, e\right) d G_{a-1, e}\left(f \mid f^{\prime}\right) \\
& -\left(1-\psi_{u}\right) p(h, a-1, e) \mathcal{I}_{u}(h, a, f, e) \\
& +\psi_{u} \int_{f^{\prime}} u\left(h+1, a, f^{\prime}, e\right) d G_{a-1, e}\left(f \mid f^{\prime}\right) \\
& -\psi_{u} p(h, a-1, e) \mathcal{I}_{u}(h+1, a, f, e)
\end{aligned}
$$

Step 13. Return to Step 9 until $a=n a$.

\subsection{Educational choice}

Step 14. Given value function $U(h, a, f, e)$, compute the optimal education decision:

$$
\begin{aligned}
e_{\epsilon}^{\star} & =\underset{e \in \Omega_{e}}{\arg \max } \Pi(x, e) \\
\text { with } \Pi(\epsilon, e) & =\mathbb{1}_{e \neq e_{1}} \sum_{a=a_{0}}^{a_{0}+d_{e}} \beta^{a-1}\left(z_{e}-\kappa(e, \epsilon)\right)+\beta^{a_{0}+d_{e}} U\left(e, a_{0}+d_{e}, f_{1}\right)
\end{aligned}
$$

Note that we assume the family status is $f_{1}$ (no child).

Step 15. Compute the proportion of skilled and unskilled.

$$
\begin{aligned}
\Gamma_{e_{2}} & =\int \mathbb{1}\left\{\Pi\left(\epsilon, e_{2}, t\right)>\Pi\left(\epsilon, e_{1}, t\right)\right\} d P(\epsilon) \\
\text { and } \Gamma_{e_{1}} & =1-\Gamma_{e_{2}}
\end{aligned}
$$

\subsection{General equilibrium}

Step 16. Compute the median income in the model at iteration $i+1$. $G W_{\text {median }}^{m, i+1}$ 
Step 17. Check if

$$
\left|\frac{G W_{\text {median }}^{m, i+1}}{G W_{\text {median }}^{m, i}}-1\right|<\varepsilon
$$

Step 18. If it is the case, stop the algorithm. Otherwise, compute $b, w_{m}, \bar{w}, \underline{w}, c_{\max }$

$$
j=\operatorname{dev}_{j} \times G W_{\text {median' }}^{m, i+1}
$$

and,

$$
\pi(h, a, f, e)=\frac{u(h, a, f, e)}{\sum_{f} u(h, a, f, e)}
$$

set $i=i+1$ and return to Step 1 .

\section{Estimation procedure}

The estimation procedure consists in finding the set of parameters that minimizes the residual function. The latter corresponds to the difference between simulated moments from the model and moments computed from the data. We apply Albertini and Terriau (2019) methodology. Table 2 summarizes the targeted life cycle series.

\subsection{Targets}

We target $L=11$ life cycle series. Each of them span 46 years, i.e. from age 20 to age 65 observed at yearly frequencies.

Table 2: SUMMARY OF TARGETS

\begin{tabular}{l}
\hline Series \\
\hline Hours worked unskilled \\
Hours worked skilled \\
Employment rate unskilled \\
Employment rate skilled \\
\hline Decile 20 of earned income of all employed workers \\
Decile 40 of earned income of all employed workers \\
Decile 60 of earned income of all employed workers \\
Decile 80 of earned income of all employed workers \\
Share of all employed workers located in the phase-in of EITC \\
Share of all employed workers located in the plateau of EITC \\
Share of all employed workers located in the phase-out of EITC \\
\hline
\end{tabular}

We denote by $\left\{\boldsymbol{Y}_{1, a}^{d}, \boldsymbol{Y}_{2, a}^{d}, \ldots, \boldsymbol{Y}_{L, a}^{d}\right\}_{a=a_{1}}^{a_{A}}$ the set of life cycle series calculated from the CPS data. 


\subsection{Estimated parameters}

The set of structural parameters is given by:

$$
\Theta=\left\{\gamma(e), \bar{\alpha}(e), \chi(e), c(e), A(e), \bar{\eta}(e), \rho(e), \psi_{n}, \psi_{u}, c_{0}, \bar{\xi}, \rho_{x}, \sigma_{x}\right\}
$$

\subsection{Minimization problem}

The strategy consists of finding the value of the parameters that best fits the life-cycle series observed in the data. Formally, the Minimization problem is written as

$$
\hat{\Theta}=\underset{\Theta}{\arg \min } \sum_{a=a_{1}}^{a_{A}} \sum_{l=1}^{L} \frac{\left.\| \boldsymbol{Y}_{l, a}^{d}-\boldsymbol{Y}_{l, a}^{m}(\Theta)\right) \|}{\boldsymbol{Y}_{l, a}^{d}}
$$

where $\boldsymbol{Y}_{i, t}^{m}(\Theta)$ are the simulated life-cycle series.

\subsection{Adaptive grid}

We use an adaptive grid to solve the above problem. It consists in constructing a wide multidimensional grid covering the space of the parameter values and refining the grid around the values that minimize the residual function. To build a multidimensional grid over $D=20$ parameters, we use low-discrepancy sequences (Halton) to generate points in space in a highly uniform manner projected inside an hyper sphere. To build this multidimensional grid we first define several variables.

- Denote by $\Theta_{1}=\left\{\theta_{1}, \theta_{2}, \ldots, \theta_{D}\right\}$ is the set of parameters with $D=\operatorname{dim}\left(\Theta_{1}\right)=20$.

- $\underline{\Theta}=\left\{\underline{\theta}_{1}, \underline{\theta}_{2}, \ldots, \underline{\theta}_{D}\right\}$ is the lower bound of the parameters.

- $\bar{\Theta}=\left\{\bar{\theta}_{1}, \bar{\theta}_{2}, \ldots, \bar{\theta}_{D}\right\}$ is the upper bound of the parameters.

- We assume that $\underline{\theta}_{d}=(1-\gamma) \theta_{d}^{0}$ and $\bar{\theta}_{d}=(1+\gamma) \theta_{d}^{0}$ with $\theta_{d}^{0}$ being initial guess for the estimated parameters and $\gamma$ a refinement parameter.

- $x(n)=\left(x_{p_{1}}(n), x_{p_{2}}(n), \ldots, x_{p_{D}}(n)\right)$ is the Halton sequence of length $n$ in a $D$ dimensional space, with $\left(p_{1}, \ldots, p_{D}\right)$ be an arbitrary co-prime integer greater than 1 and $x_{d}(n)$ is the Van der Corput sequence (one dimension).

The grid over each parameter writes:

$$
\mathcal{G}(n)=\left\{\varphi\left(\theta_{1}\right), \varphi\left(\theta_{2}\right), \ldots, \varphi\left(\theta_{D}\right)\right\}
$$

where,

$$
\varphi\left(\theta_{d}\right)=\underline{\theta}_{d}+x_{p_{d}}(n)\left(\bar{\theta}_{d}-\underline{\theta}_{d}\right)
$$

The algorithm is as follow:

1 Generate Halton sequences $x(n)$ in $D$ dimensional space 
2 Compute the Euclidian distance between $x(n)$ and the mean (0.5):

$$
D(n)=\sqrt{\sum_{d}^{D}\left(x_{p_{d}}(n)-0.5\right)^{2}}, \quad i=1, \ldots, n_{p}
$$

3 Denote by $\mathcal{P}$ an empty set such that $\mathcal{P}=\{\varnothing\}$. Eliminate from $x(n)$ all points for which $D(n)<\epsilon_{r}$ and add them to $\mathcal{P}$.

4 Apply a linear transformation:

$$
\varphi\left(\theta_{d}\right)=\underline{\theta}_{d}+x_{p_{d}}(n)\left(\bar{\theta}_{d}-\underline{\theta}_{d}\right)
$$

Figure 1 shows the step to build a grid of low-discrepancy sequences in two dimension (with $\psi_{n}$ and $\psi_{u}$ ).

Figure 1: 2 DIMENSIONS GRID
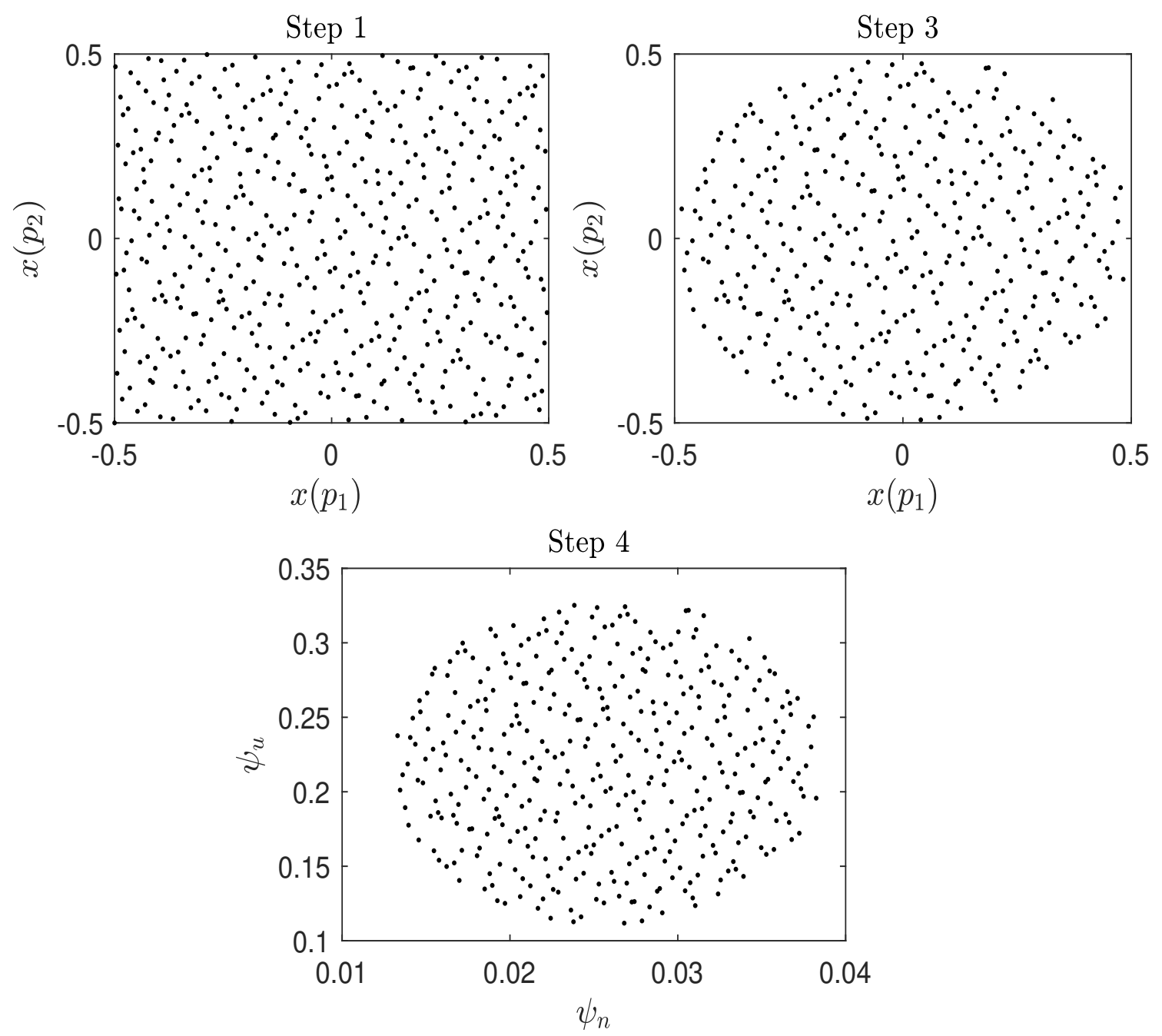


\subsection{Algorithm}

Step 1: Set iteration number $k=1$ and set initial value of the bounds $\underline{\Theta}$ and $\bar{\Theta}$ for the parameters. Compute the multidimensional grid $\mathcal{G}(n)$ using Halton sequence. Set the refinement parameter $\gamma^{k}<1$ and the initial value of the residual function $\mathcal{R}^{k}$.

Step 2: Solve the model for each combination of parameters and compute the residual function for each parameter combination $\mathcal{R}^{k}(\mathcal{G}(n))$ :

Step 3: Find the node $n^{\star}$ from $\mathcal{G}(n)$ that minimizes the residual function.

Step 4: Compute the difference between the residual function at $k$ and $k+1$ :

$$
\Delta^{k+1}=\frac{\left\|\mathcal{R}\left(\mathcal{G}\left(n^{\star k+1}\right)\right)^{k+1}-\mathcal{R}\left(\mathcal{G}\left(n^{\star k}\right)\right)^{k}\right\|}{\left\|\mathcal{R}\left(\mathcal{G}\left(n^{\star k}\right)\right)^{k}\right\|}
$$

Step 5: If $\Delta^{k+1} \leq \tilde{\varepsilon}$ stop the algorithm. Otherwise, refine the grid of the parameters using the following updating scheme:

a. Set $k=k+1$.

b. Compute $\gamma^{k}$ and the new lower band and upper band of estimated parameters : $\underline{\Theta}=\left(1-\gamma^{k}\right) \mathcal{G}\left(n^{\star k-1}\right)$ and $\bar{\Theta}=\left(1+\gamma^{k}\right) \mathcal{G}\left(n^{\star k-1}\right)$

c. Compute new Halton sequences for each parameter

$$
\varphi\left(\theta_{d}\right)=\underline{\theta}_{d}+x_{p_{d}}(n)\left(\bar{\theta}_{d}-\underline{\theta}_{d}\right)
$$

d. Compute the multidimensional grid as:

$$
\mathcal{G}(n)=\left\{\varphi\left(\theta_{1}\right), \varphi\left(\theta_{2}\right), \ldots, \varphi\left(\theta_{D}\right)\right\}
$$

\section{Simulation - transitional dynamics}

We describe the simulation procedure to get the transitional dynamics of the model. It consists in finding the path of the variables from one steady state (benchmark) to the new steady state $(2 \times$ EITC). We assume that the change in EITC is unexpected. The objective is to find the variables of the model at each period $t$.

The simulation of the transitional dynamics takes advantage of the recursive structure of the model and, in particular, the life cycle aspect. Indeed, each period $t, t+$ $1, \ldots, t+n$ involves an increase in age of the individual by one period $a$. As the two periods ( $a$ and $t$ ) moves at the same frequency, one can easily track each individual at each age.

\subsection{Notations}

- $\boldsymbol{u}(h, a, f, e, t)$ and $\boldsymbol{n}(h, a, f, x, e, t)$ are the time-varying distribution or, equivalently, the transitional dynamics of unemployment and employment respectively. 
- The initial conditions are given by

$$
\begin{aligned}
\boldsymbol{u}(h, a, f, e, 1) & =u(h, a, f, e) \\
\boldsymbol{u}(h, a, f, x, e, 1) & =n(h, a, f, x, e)
\end{aligned}
$$

- Let $k$ be any (endogenous) decision variable in the benchmark model and $\bar{k}$ be the same variable in the alternative scenario $(2 \times$ EITC). Here,

$$
k=\left\{s\left(h, a-1, f^{\prime}, e\right), \mathbb{1}\{h, a, f, x, e\}, p(h, a-1, e)\right\}
$$

- Today's (period $t$ ) decision variable is given by,

$$
k^{*}= \begin{cases}k & \text { if } \\ \bar{k} & \text { otherwise }\end{cases}
$$

where $t^{\star}$ is the date at which the EITC switch from $c_{\max }$ to $c_{\max }^{\prime}=2 c_{\max }$. We assume that the increase in $c_{\max }$ occurs in one period and is not delayed.

\subsection{Interpolation}

Due to the presence of the law motion of unemployment in the Bellman equation of a vacant job one need to rely on interpolation techniques. Indeed, the value of a vacant job writes:

$$
V(h, a, e)=-c_{e}+\beta\left[\begin{array}{l}
q(h, a, e) \iint_{0, e} \pi\left(h, a, f^{\prime}, e\right) \Lambda\left(h, a^{\prime}, f^{\prime}, x^{\prime}, e\right) d Z_{0}\left(x^{\prime}\right) d f^{\prime} \\
+(1-q(h, a, e)) \max _{h, a, e} V(h, a, e)
\end{array}\right],
$$

where $\pi(h, a, f, e)$ is the proportion of unemployed workers with family status $f$ :

$$
\pi(h, a, f, e)=\frac{u(h, a, f, e)}{\int u(h, a, f, e) d f} .
$$

Because unemployment $\boldsymbol{u}(h, a, f, e, t)$ now depends on time $t$, all control variables become time-dependent. While it is possible to derive the transitional dynamics by iterating forward the law of motion and by iterating backward the decision rules, and by repeating this procedure until convergence of the entire transitional dynamics, it is a very long and complicated task.

Instead, we proceed by using interpolation techniques. This procedure can be implemented as the distribution of unemployment only appears in the job creation condition through $\pi(h, a, f, e)$. In particular, we follow the algorithm below:

(1) Compute the steady state of the decision rule and the stationary distributions under the benchmark calibration and under the alternative scenario $(2 \times$ EITC).

(2) For each $h, a, f, e$ interpolate $\pi(h, a, f, e)$ and $\bar{\pi}(h, a, f, e)$ using the following procedure:

$$
\begin{aligned}
& \pi(h, a, f, e, \iota)=\pi(h, a, f, e)+\iota \frac{\bar{\pi}(h, a, f, e)-\pi(h, a, f, e)}{I-1} \\
& \quad \iota=1, \ldots, I
\end{aligned}
$$

Note that we can consider larger deviations than that implied by the difference between $\pi(h, a, f, e)$ and $\bar{\pi}(h, a, f, e)$. 
(3) Solve the decision rules for each value of $\pi(h, a, f, e, \iota)$

$$
k(\iota)=\left\{s\left(h, a-1, f^{\prime}, e, \iota\right), \mathbb{1}\{h, a, f, x, e, \iota\}, p(h, a-1, e, \iota)\right\}
$$

The main idea of this strategy is that when simulating the transitional dynamics, we iterate on the law of motion. Then, each period $t$ we obtain a value for unemployment $\boldsymbol{u}(h, a, f, e, t)$ and a value for the proportion of unemployed workers $\boldsymbol{\pi}(h, a, f, e, t)$. Consequently, our objective is to find the correct policy rule $k\left(\iota^{*}\right)$ such that:

$$
\iota=\arg \min _{\iota}(\boldsymbol{\pi}(h, a, f, e, t)-\pi(h, a, f, e, \iota))
$$

\subsection{Law of motion}

Integrals can be recomputed as:

$$
\begin{aligned}
\mathcal{I}_{n}(h, a, f, x, e, t) & =\int_{f^{\prime}} \int_{x^{\prime}} n\left(h, a-1, f^{\prime}, x^{\prime}, e, t-1\right) d Z\left(x \mid x^{\prime}\right) d G_{a-1, e}\left(f \mid f^{\prime}\right) \\
\mathcal{I}_{u}(h, a, f, e, t) & =\int_{f^{\prime}} \int_{x^{\prime}} u\left(h, a-1, f^{\prime}, e, t-1\right) s^{*}\left(h, a-1, f^{\prime}, e, \iota\right) d Z_{0}\left(x^{\prime}\right) d G_{a-1, e}\left(f \mid f^{\prime}\right)
\end{aligned}
$$

The law motion for employment is given by:

$$
\begin{aligned}
\boldsymbol{n}(h, a, f, x, e, t)= & \mathbb{1}^{*}\{h, a, f, x, e, \boldsymbol{\iota}\}\left[\psi_{n}\left(1-\delta_{e}\right) \mathcal{I}_{n}(h-1, a, f, x, e, t)\right. \\
& +\left(1-\psi_{n}\right)\left(1-\delta_{e}\right) \mathcal{I}_{n}(h, a, f, x, e, t) \\
& +\psi_{u} p^{*}(h, a-1, e, \iota) \mathcal{I}_{u}(h+1, a, f, e, t) p^{*}(h, a-1, e, \iota) \\
& \left.+\left(1-\psi_{u}\right) p^{*}(h, a-1, e, \iota) \mathcal{I}_{u}(h, a, f, e, t)\right]
\end{aligned}
$$

The law motion for unemployment is given by:

$$
\begin{aligned}
\boldsymbol{u}(h, a, f, e, t)= & \left(1-\psi_{n}\right) \int_{x}\left(\delta_{e}+\left(1-\mathbb{1}^{*}\{h, a, f, x, e, \boldsymbol{\iota}\}\right)\right) \mathcal{I}_{n}(h, a, f, x, e, t) d x \\
& +\psi_{n} \int_{x}\left(\delta_{e}+\left(1-\mathbb{1}^{*}\{h, a, f, x, e, \boldsymbol{\iota}\}\right)\right) \mathcal{I}_{n}(h-1, a, f, x, e, t) d x \\
& +\left(1-\psi_{u}\right) \int_{f^{\prime}} \boldsymbol{u}\left(h, a-1, f^{\prime}, e, t-1\right) d G_{a-1, e}\left(f \mid f^{\prime}\right) \\
& -\left(1-\psi_{u}\right) p^{*}(h, a-1, e, \iota) \mathcal{I}_{u}(h, a, f, e, t) \\
& +\psi_{u} \int_{f^{\prime}} \boldsymbol{u}\left(h+1, a-1, f^{\prime}, e, t-1\right) d G_{a-1, e}\left(f \mid f^{\prime}\right) \\
& -\psi_{u} p^{*}(h, a-1, e, \iota) \mathcal{I}_{u}(h+1, a, f, e, t)
\end{aligned}
$$

